\title{
Influence of casting condition on the anisotropy of the fracture properties of Steel Fibre Reinforced Self-Compacting Concrete (SFRSCC)
}

\author{
Rodrigo Lameiras ${ }^{\mathrm{a}, *}$, Joaquim A.O. Barros ${ }^{\mathrm{b}, 1}$, Miguel Azenha ${ }^{\mathrm{b}, 1}$ \\ a ILATIT, UNILA - Universidade Federal da Integração Latino-Americana, Foz do Iguaçu, Paraná 85867-970, Brazil \\ ${ }^{\mathrm{b}}$ ISISE, Dep. Civil Eng., School Eng., Universidade do Minho, Campus de Azurém, Guimarães 4800-058, Portugal
}

\section{A R T I C L E I N F O}

\section{Article history:}

Received 7 September 2014

Received in revised form 16 January 2015

Accepted 3 March 2015

Available online 11 March 2015

\section{Keywords:}

Steel Fibre Reinforced Self-Compacting

Concrete

Tensile constitutive behaviour

Post-cracking behaviour

Stress-crack width constitutive law

Dispersion of fibres

Orientation of fibres

\begin{abstract}
A B S T R A C T
Identification of the tensile constitutive behaviour of Fibre Reinforced Concrete (FRC) represents an important aspect of the design of structural elements using this material. Although an important step has been made with the introduction of guidance for the design with regular FRC in the recently published fib Model Code 2010, a better understanding of the behaviour of this material is still necessary, mainly for that with self-compacting properties. This work presents an experimental investigation employing Steel Fibre Reinforced Self-Compacting Concrete (SFRSCC) to cast thin structural elements. A new test method is proposed for assessing the post-cracking behaviour and the results obtained with the proposed test method are compared with the ones resulted from the standard three-point bending tests (3PBTs). Specimens extracted from a sandwich panel consisting of SFRSCC layers are also tested. The mechanical properties of SFRSCC are correlated to the fibre distribution by analysing the results obtained with the different tests. Finally, the stress-crack width constitutive law proposed by the fib Model Code 2010 is analysed in light of the experimental results.
\end{abstract}

(c) 2015 Elsevier Ltd. All rights reserved.

\section{Introduction}

The use of fibre reinforcement for concrete structures is a steadily increasing technology that is competitive in several applications. It is particularly attractive for statically indeterminate structures, since cracking control through fibre reinforcement mechanisms can provide high levels of stress redistribution, leading to load carrying capacity and deformability levels that are much higher than the cracking load and its corresponding deformation. In fact the energy dissipated on the concrete fracture propagation is the property that most benefits from including fibre reinforcement. This dissipated energy is, however, quite dependent on the fibre orientation and distribution [1-4].

Therefore, accurate design approaches require the knowledge of fibre dispersion and orientation that is expected to be found into the structural element. These two parameters are, however, governed by several factors like: mixing and placing technology of Fibre Reinforced Concrete (FRC), rheology of FRC, geometric and mechanical properties of the FRC constituents, mainly of fibres, and geometry of the structure [5-12]. These aspects are even more

\footnotetext{
* Corresponding author. Tel.: +55 4535292834 .

E-mail address: rmlameiras@gmail.com (R. Lameiras).

1 Tel.: +351 253510 200; fax: +351253510 217 .
}

relevant in Steel Fibre Reinforced Self-Compacting Concrete (SFRSCC), due to the high flowability of this composite and the higher density of these relatively stiff fibres, leading to the tendency of fibres to align orthogonally to the concrete flux lines, as well as to sink into the SCC medium [13-18].

Several test methods have been proposed to assess the fracture mode I of the post-cracking behaviour of FRCs [19-23]. These methods are, in general, based on direct assessment (e.g. uniaxial tensile tests) or indirect approaches through bending, indirect tensile (Brazilian) and plate tests. These indirect approaches require further procedures to derive the constitutive law that, eventually, can simulate the fracture mode I propagation in FRC. Fracture mode I is characterized by the stress at crack initiation, $\sigma_{c r}$, the fracture energy, $G_{f}$, and the shape of the stress $(\sigma)$ versus crack width $(w)$ diagram, $\sigma-w$. $G_{f}$ corresponds to the energy dissipated on the formation of a unit area of crack surface, i.e., the area between the $\sigma-w$ diagram and the abscissa axis representing the crack width, up to the ultimate crack width, $w_{u}$, that corresponds to null tensile stress:

$G_{f}=\int_{0}^{w_{u}} \sigma(w) \cdot d w$

A direct tensile test under closed-loop displacement control is the most suitable method to determine $G_{f}$ of a material [24]. This test generally uses notched specimens in order to create a weaker 
section, inducing the appearance of a single crack across the notched section of the specimen and favoring a more stable test. This increased stability is related to the fact that the control system generally follows the signal recorded in displacement transducers that are almost exclusively measuring the crack opening at the notched section [24,25]. However, due to the fibre pullout reinforcement mechanisms, mainly when using relatively long fibres, $w_{u}$ is generally not attained in FRCs, resulting in estimated values of $G_{f}$ that can be lower than the ones that actually characterize the material $[25,26]$. In an opposite way, a unique fracture surface is almost impossible to be guaranteed in FRCs, mainly when strain hardening cement composites are tested [27], therefore the evaluated $G_{f}$ can result in overestimations.

Apart these concerns on the evaluation of $G_{f}$, the direct tensile test is expensive and time consuming. Moreover, there is a multiplicity of technical problems that make the uniaxial tensile test difficult to be performed, namely the perfect alignment of the specimen with the actuator in order to avoid undesired bending, and the difficulties of properly fixing the specimen to the equipment $[3,24,25,28-30]$.

Owing to the difficulties in performing direct tensile tests, standard test methods for assessing the post-cracking behaviour are generally based on notched beam bending tests [20-22,31]. Three and four point bending tests (3PBT and 4PBT, respectively) are commonly adopted. Among the different standards and proposals, differences can also be found in the size of specimens and in the presence or absence of a notched section. In spite of its simplicity, this type of test is known to have limitations, such as the necessity of performing inverse analysis procedures to obtain the stress versus crack opening relationship $(\sigma-w)$. Furthermore, in the case of SFRSCC testing, the standardized geometries and casting procedures can conduct to a material that is not representative of the SFRSCC employed in the actual structure. This is aggravated in the cases where SFRSCC is used in thin structural elements (e.g. shell structures) [13,32].

In an attempt to avoid the limitations of the aforementioned tests, Ozyurt et al. [33] and Carmona and Aguado [34] proposed the adoption of Splitting Tensile Test (STT), also known as Brazilian test, to evaluate the post cracking behaviour of FRC. This is a relatively simple test method in which the specimen can be obtained through drilling (either from a prototype, or even from the actual structure). The main limitation of this test is the fact that it is an indirect test, with the overlapping of compressive and tensile stresses at the fractured section of specimen.

Seeking the advantages of the splitting test, and trying to minimize its limitations, some authors proposed similar alternatives, like the Double Edge Wedge Splitting (DEWS) test and the Modified Splitting Tensile Test (MSTT).

The DEWS test was originally conceived by Brühwiler and Wittmann [35] for plain concrete, and was recently suggested by di Prisco et al. [36] for the characterization of FRC. It consists of a rectangular specimen with angular notches at the proximity of the load application. This test aims to assure absence of accompanying compression fields perpendicularly to the load direction in the central region of the specimen by adopting angular notches in its loaded regions. These notches also induce the formation of only one fracture plane in the central part of specimen.

In turn, the MSTT was introduced by a group of researchers from the University of Minho [17]. It consists on the use of a cylinder specimen with vertical notches along the loading plane, obtaining a weakened section in the middle of specimen.

The main differences between the DEWS and MSTT are the geometry of the specimens (cylindrical for MSTT and prismatic with square section for DEWS), and the process used to form the fracture plane at the middle of specimen. An advantage of the DEWS is the fact that in this test the crosswise compressive stresses are deviated from the ligament by means of the angular notches and a pure mode I fracture is likely to be induced along the fractured section. Nevertheless, despite the actions taken to induce only one fracture surface, the formation of multiple parallel cracks has been reported by di Prisco et al. [36] for some tests made adopting the DEWS.

The DEWS and MSTT have been used to evaluate the influence of the FRC flowability on the fibre distribution and orientation, and corresponding consequences on the fracture properties of this composite [9,10,13,14,33,37-41]. Analytical and numerical approaches have been also presented in this respect, respectively, by Laranjeira et al. [42] and Cunha et al. [43]. Nonetheless, it is still not clear for structural designers how these aspects should be taken into consideration while designing a structural element made with SFRSCC.

In the present work experimental tests were carried out with standard 3PBT specimens, with specimens extracted from prototypes and from real scale sandwich panels formed by outer SFRSCC layers and a polystyrene foam core (thermal insulation). A new test method, which arose from adaptation of DEWS and MSTT test methods was proposed. The tests were planned for assessment of the influence of casting conditions on fibre distribution and orientation. Finally, the results obtained from the different tests are compared in order to discuss the capacity of the different characterization tests in regard to modelling SFRSCC behaviour of actual structures where such material is applied.

\section{Research significance}

This paper aims to contribute for a reliable assessment of the stress-crack width relationship of SFRSCC that can be used for the design of structures made by thin layers of this composite, namely in the case of sandwich panels. The main contributions of the paper are:

- propose a new test method that arose from combination of MSTT and DEWS. The proposed method tries to overcome the limitations of each test method, deviating the crosswise compressive stresses from the fractured section while a unique fracture plane is likely to be obtained.

- Evaluate the validity of a widely used 3PBT method for the characterization of fracture properties of FRC of the SFRSCC applied in the aforementioned structure types;

- perform a critical analysis on the stress-crack width constitutive relationship proposed by the fib Model Code 2010 $[44,45]$, by using the experimental results obtained with the different test setups.

\section{Post-cracking characterization of steel fibre reinforced concrete (SFRC)}

\subsection{RILEM TC 162-TDF recommendations}

For the characterization of the post-cracking behaviour of SFRC, RILEM TC 162-TDF initially recommended the evaluation of the equivalent flexural tensile strength parameters, one to be used for the design at serviceability limit states, $f_{e q, 2}$, and the other for the design at ultimate limit states, $f_{e q, 3}$, in regard to reference vertical deflections $(\delta)$ during the experiment $[46,47]$. Later, RILEM TC 162-TDF has proposed the replacement of $f_{\text {eq }}$ for the concept of residual flexural tensile strength, $f_{R}$, which gives the stress for distinct deflections or crack mouth opening displacements, (CMOD) [20]. Although this last concept has the advantage of being easier to evaluate, it is more susceptible to the irregularities of the force-deflection relationships registered in the tests. 
The specimen geometry proposed by RILEM TC 162-TDF recommendations [20] is shown in Fig. 1. For specific information on the method for casting the specimens, the curing procedures, the position and dimensions of the notch sawn into the specimen, the loading and specimen support conditions, the characteristics for both the equipment and measuring devices and the test procedures, the reader is forwarded to the RILEM TC 162-TDF recommendations. Such specific information has been omitted here for the sake of brevity.

A typical force $(F)$ deflection $(\delta)$ relationship, $F-\delta$, for this 3PBT testing procedure is shown in Fig. 2. If a displacement transducer is mounted at the notch mouth, the F-CMOD relationship can also be recorded. Using these relationships, RILEM TC 162-TDF proposed the evaluation of the load at the limit of proportionality $\left(F_{L}\right)$, the equivalent $\left(f_{e q, 2}\right.$ and $\left.f_{e q, 3}\right)$ and the residual $\left(f_{R, 1}\right.$ and $\left.f_{R, 4}\right)$ flexural tensile strength parameters $[46,48] . F_{L}$ is the highest value of the load recorded up to a deflection (or CMOD) of $0.05 \mathrm{~mm}$. The parameters $f_{\text {eq, } 2}$ and $f_{\text {eq, } 3}$ are related to the material energy absorption capacity up to a deflection of $\delta_{2}$ and $\delta_{3}\left(\delta_{2}=\delta_{L}+0.65 \mathrm{~mm}\right.$ and $\delta_{3}=\delta_{L}+2.65 \mathrm{~mm}$, where $\delta_{L}$ is the deflection corresponding to $F_{L}$ ) provided by fibre reinforcement mechanisms $\left(D_{B Z, 2}^{f}\right.$ and $\left.D_{B Z, 3}^{f}\right)$, as seen in Fig. 2. $D_{B Z, 2}^{f}$ and $D_{B Z, 3}^{f}$ are computed following the procedures described elsewhere [46]. The parameters $f_{R, 1}$ and $f_{R, 4}$ are the stresses for the forces $F_{R, 1}$ and $F_{R, 4}$, respectively, at deflection of $\delta_{R, 1}=0.46 \mathrm{~mm}$ and $\delta_{R, 4}=3.0 \mathrm{~mm}$. According to RILEM TC 162TDF, the limit of proportionality $\left(f_{f c t, L}\right)$, the equivalent [46] and the residual [20] flexural tensile strength parameters are obtained from the following equations:

$f_{f c t, L}=\frac{3}{2} \frac{F_{L} L}{b h_{s p}^{2}} \quad\left(\mathrm{~N} / \mathrm{mm}^{2}\right)$

$f_{R, 1}=\frac{3}{2} \frac{F_{R, 1} L}{b h_{s p}^{2}} ; f_{R, 4}=\frac{3}{2} \frac{F_{R, 4} L}{b h_{s p}^{2}} \quad\left(\mathrm{~N} / \mathrm{mm}^{2}\right)$

$f_{e q, 2}=\frac{3}{2} \frac{D_{B Z, 2}^{f}}{0.50} \frac{L}{b h_{s p}^{2}} ; f_{e q, 3}=\frac{3}{2} \frac{D_{B Z, 3}^{f}}{2.50} \frac{L}{b h_{s p}^{2}} \quad\left(\mathrm{~N} / \mathrm{mm}^{2}\right)$

where $b(=150 \mathrm{~mm})$ and $L(=500 \mathrm{~mm})$ are the width and the span of the specimen, and $h_{s p}(=125 \mathrm{~mm})$ is the distance between the tip of the notch and the top of the cross section.

\section{2. fib Model Code 2010 recommendations}

While the RILEM approach makes use of equivalent flexural tensile strength parameters $\left(f_{e q, 2}\right.$ and $\left.f_{e q, 3}\right)$, the fib Model Code 2010 is based solely on the residual parameters $\left(f_{R, j}\right)$. Furthermore, in the fib Model Code 2010 the deformations are expressed in terms of
CMOD, not being necessary to measure deflections, as recommended by the RILEM TC 162-TDF [46].

A typical Force-CMOD relationship obtained from a three-point beam bending test following the fib recommendations is represented in Fig. 3. The geometry and the production of the specimen are the same ones recommended by RILEM TC 162 TDF, as well as the loading and support conditions [46].

Based on the force values for the $\mathrm{CMOD}_{j}(j=1-4$, see Fig. 3$)$, the corresponding force values, $F_{R, j}$, are obtained, and the derived residual flexural tensile strength parameters are determined from the following equation:

$f_{R, j}=\frac{3 F_{R, j} L}{2 b h_{s p}^{2}}$

where $f_{R, j}\left(\mathrm{~N} / \mathrm{mm}^{2}\right)$ and $F_{R, j}(\mathrm{~N})$ are, respectively, the residual flexural tensile strength and the load corresponding to $\mathrm{CMOD}=\mathrm{CMOD}_{j}(\mathrm{~mm})$.

\section{Experimental study}

\subsection{SFRSCC: mixtures and basic characterization}

The constituent materials used in the composition of the studied concretes are: Cement CEM I 42.5R $(C)$, water $(W)$, superplasticizer of third generation $(S)$ based on polycarboxylates (SIKA $3005 \mathrm{HE}$ ), limestone filler $\left(L_{F I}\right)$, fine river sand $\left(F_{R S}\right)$, coarse river sand $\left(C_{R S}\right)$, limestone coarse aggregate $\left(L_{C A}\right)$ and hooked end steel fibres. The steel fibres are characterized by a length $\left(L_{f}\right)$ equal to $35 \mathrm{~mm}$, a diameter $\left(d_{f}\right)$ equal to $0.55 \mathrm{~mm}$, and an aspect ratio $\left(\lambda_{f}=L_{f} / d_{f}\right)$ of 65 . According to the data given by the supplier, the yield stress of the steel fibres is $1244-1446 \mathrm{MPa}$.

The mix composition has followed the procedures described elsewhere [49] in order to take into account the influence of the fibre content and properties on the skeleton organization of the aggregates, and the paste percentage. The content of steel fibres $\left(S_{F B}\right)$ in all SFRSCC used in this research is kept constant and equal to $60 \mathrm{~kg} / \mathrm{m}^{3}$. The present research is carried out considering data from tests performed with specimens obtained from different castings, but made with similar SFRSCC. They consist of the same constituent materials and with slightly different water contents, as shown in Table 1 . The differences in the water content among the different castings were caused by adjustments to compensate the different moisture condition of the aggregates. In Table $1, W$ represents the total water content of the concrete used in the respective casting.

For all the castings, the flow spread of SFRSCC $\left(D_{f l}\right)$ in the fresh state was registered by using the inverted Abrams cone and following the recommendations of EFNARC [50]. The obtained results are shown in Table 2. An average value of $672.5 \mathrm{~mm}$ was obtained. The authors believe that the relatively reduced spread obtained in

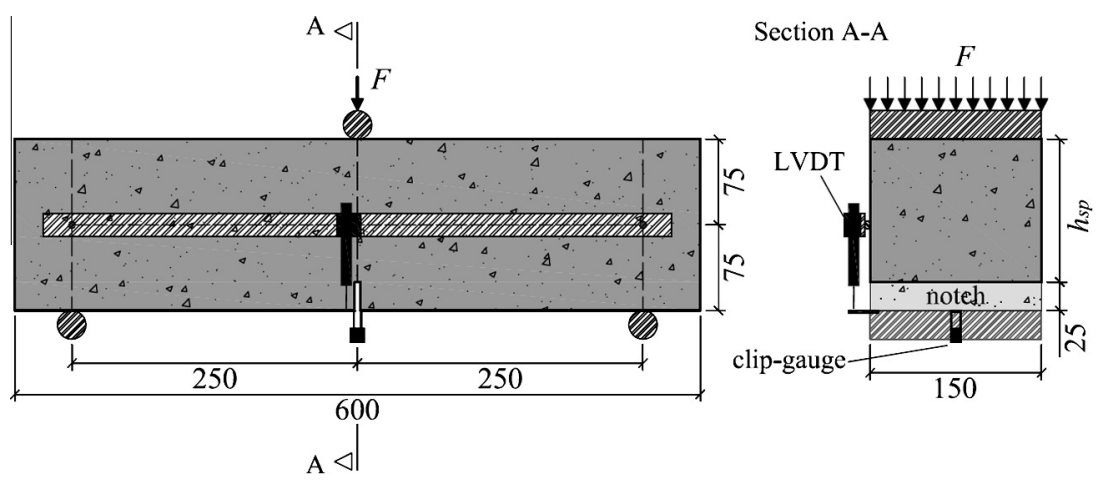

Fig. 1. Three-point bending test setup [46] (units in millimetres). 


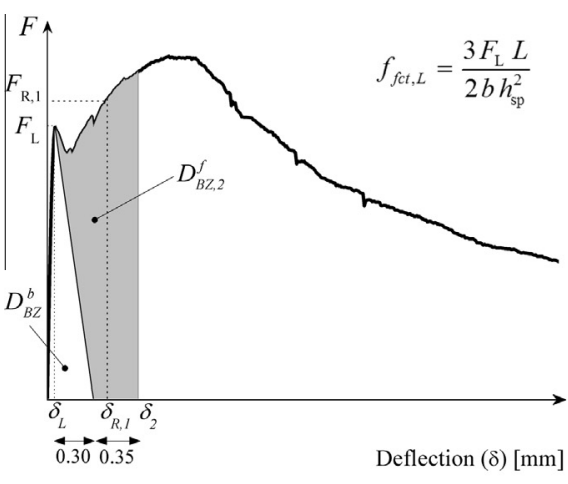

(a)

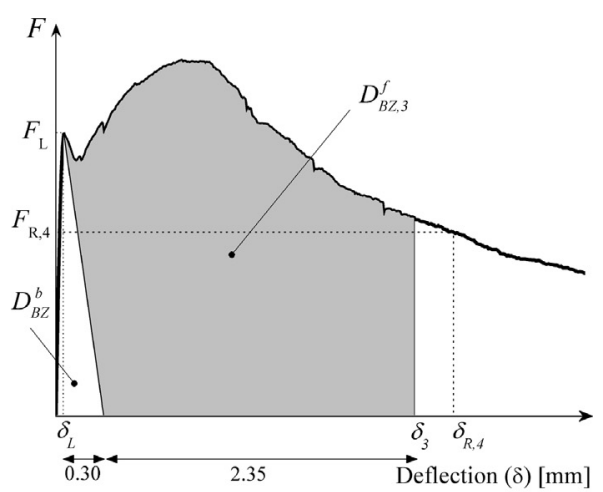

(b)

Fig. 2. Evaluation of: (a) $f_{e q, 2}$ and $f_{R, 1}$, (b) $f_{\text {eq,3 }}$ and $f_{R, 4}$ flexural tensile strength parameters according to RILEM TC 162-TDF [20,46].

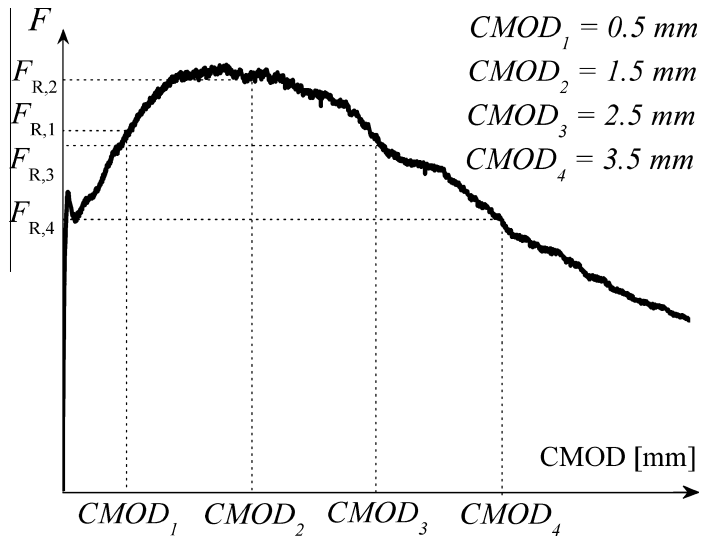

Fig. 3. Typical load F-CMOD curve for FRC $[44,45]$.

Table 1

Compositions of the concretes used in this research.

\begin{tabular}{|c|c|c|c|c|c|c|c|c|}
\hline Casting & $C(\mathrm{~kg})$ & $W(\mathrm{~kg})$ & $S(\mathrm{~kg})$ & $L_{F I}(\mathrm{~kg})$ & $F_{R S}(\mathrm{~kg})$ & $C_{R S}(\mathrm{~kg})$ & $L_{C A}(\mathrm{~kg})$ & $S_{F B}(\mathrm{~kg})$ \\
\hline $8-10$ & & 148.0 & & & & & & \\
\hline 11 & & 179.1 & & & & & & \\
\hline 12 & 413 & 186.9 & 7.83 & 353 & 233 & 700 & 582 & 60 \\
\hline $13-15$ & & 174.7 & & & & & & \\
\hline $16-19$ & & 182.4 & & & & & & \\
\hline
\end{tabular}

casting 10 was caused by the higher period of time between its mixing phase and the flow test.

The compressive strength $\left(f_{c m}\right)$ and the elastic modulus $\left(E_{c m}\right)$ of the SFRSCC were determined using cylinders of $150 \mathrm{~mm}$ diameter and $300 \mathrm{~mm}$ height. The tests of specimens from different castings were carried out at the ages indicated in Table 2. The number of specimens adopted are also indicated in Table 2. All the specimens were cured under laboratory temperature and humidity conditions (mean average ambient temperature at the curing period equal to $15^{\circ} \mathrm{C}$ ). The compressive tests were carried out under displacement control, in order to obtain the complete load-displacement curve, and therefore evaluate the strain upon reaching the compressive strength $\left(\varepsilon_{c 1}\right)$ and the energy dissipated in compression $\left(G_{c}\right)$. Details about how these parameters are computed can be found elsewhere [3]. The elasticity modulus is determined following the procedures described by the Portuguese standard LNEC E397 [51] that are similar to the procedures of other standards, such as RILEM TC 14-CPC [52] and ASTM C469 [53]. The obtained values for the compressive strength and elasticity modulus are given in Table 2. It is observed that the coefficients of variation of the results of compressive tests were high, and the differences registered amongst the groups are also significant, mainly between the casting group 8-10 and the remaining castings. Nevertheless, the authors believe that this is a minor issue for the main objectives of the present research, since in spite of the recognized favourable effect of the compressive strength on a better mobilization of the reinforcement mechanisms, the available research in this respect suggests that the obtained differences do not have significant impact in this context, as long as the fibre failure mode is not changed, such was the case [54].

\subsection{Three-point bending test (3PBT)}

A total of 40 beams of size $150 \times 150 \times 600 \mathrm{~mm}^{3}$ were cast according to the recommendations of EN 14651 standard [21] by using SFRSCC from the castings presented in Table 1 . The beams were notched at midspan by using a saw-cut equipment. The depth of the notch was about $25 \mathrm{~mm}$ along the width of the specimen's cross section. The final dimensions of all the specimens were measured and were taken into consideration on the evaluation of the results.

Three-point bending tests (3PBTs) on notched specimens were carried out in accordance with the recommendations of RILEM Technical Committee TC 162-TDF [20] - see schematic representation and photo in Fig. 4. The tests were performed under displacement control in a servo-hydraulic testing machine by using a linear transducer (LVDT). Until a deflection of $1 \mathrm{~mm}$, the test was performed at a constant rate of $0.2 \mathrm{~mm} / \mathrm{min}$. When this deflection was reached, the deflection rate was increased to $0.4 \mathrm{~mm} / \mathrm{min}$. Two additional LVDTs were used to measure the Crack Mouth Open Displacement (CMOD) placed at the locations shown in Fig. 4a. Following the recommendations of RILEM TC 162-TDF in terms of the loading and casting directions, the deflection and the CMOD were measured as illustrated in Fig. 4. The $\mathrm{CMOD}_{\mathrm{T}}$ and $\mathrm{CMOD}_{\mathrm{B}}$ represent, respectively, the CMOD registered in the top and bottom surfaces considered in the casting process of the specimen.

From the 3PBT, the following results were computed: limit of proportionality $\left(f_{f c t, L}\right)$; equivalent flexural tensile strength $\left(f_{e q, 2}\right.$ and $f_{e q, 3}$ ) and residual flexural tensile strengths. These results were obtained corresponding to the following the CMOD equal to 0.5 , $1.5,2.5$ and $3.5 \mathrm{~mm}\left(f_{R, 1}, f_{R, 2}, f_{R, 3}\right.$ and $f_{R, 4}$, respectively), as recommended by the fib Model Code. All the 3PBT were performed up to a midspan deflection equal to $4.0 \mathrm{~mm}$, which was verified to be almost coincident to a crack width of $4.0 \mathrm{~mm}$, what was already expected based on the relationships between deflection and CMOD reported in the literature [46]. The 3PBT were always conducted 28 days after the casting of specimens. 
Table 2

Average values (Avg.) and coefficient of variation ( $\mathrm{CoV})$ for the flow spread of fresh concrete, compressive strength $\left(f_{c m}\right)$ and elastic modulus $\left(E_{c m}\right)$.

\begin{tabular}{|c|c|c|c|c|c|c|c|c|c|}
\hline \multirow{3}{*}{$\begin{array}{l}\text { Casting number } \\
8\end{array}$} & \multirow{3}{*}{$\begin{array}{l}\text { Slump flow } \\
D_{f l}(\mathrm{~mm}) \\
620\end{array}$} & \multicolumn{4}{|c|}{ Compressive test } & \multicolumn{4}{|c|}{ Elastic modulus test } \\
\hline & & \multirow{2}{*}{$\begin{array}{l}\text { Age (days) } \\
31\end{array}$} & \multirow{2}{*}{$\begin{array}{l}\text { N. of spec. } \\
2\end{array}$} & \multicolumn{2}{|c|}{$\begin{array}{l}f_{\mathrm{cm}}(\mathrm{MPa}) \\
\text { Avg. }(\mathrm{CoV})\end{array}$} & \multirow{2}{*}{$\begin{array}{l}\text { Age (days) } \\
31\end{array}$} & \multirow{2}{*}{$\begin{array}{l}\text { N. of spec. } \\
2\end{array}$} & \multicolumn{2}{|c|}{$\begin{array}{l}E_{c m}(\mathrm{GPa}) \\
\text { Avg. }(\mathrm{CoV})\end{array}$} \\
\hline & & & & 45.48 & $(2.5 \%)$ & & & 33.93 & $(0.6 \%)$ \\
\hline 9 & 700 & 31 & 1 & 44.74 & $(0.0 \%)$ & 31 & 2 & 34.03 & $(0.3 \%)$ \\
\hline 10 & 485 & 94 & 4 & 45.60 & $(8.5 \%)$ & 94 & 2 & 34.60 & (3.5\%) \\
\hline 11 & 600 & 66 & 4 & 56.39 & $(3.4 \%)$ & 66 & 2 & 35.06 & $(10.5 \%)$ \\
\hline 12 & 715 & 66 & 3 & 61.23 & $(2.5 \%)$ & 66 & 2 & 35.89 & (16.1\%) \\
\hline 13 & 680 & 67 & 4 & 61.94 & $(5.2 \%)$ & 67 & 2 & 41.61 & $(0.6 \%)$ \\
\hline 14 & 650 & 64 & 4 & 60.22 & (3.3\%) & 64 & 2 & 41.17 & (3.3\%) \\
\hline 15 & 660 & 52 & 4 & 60.06 & $(7.2 \%)$ & 52 & 2 & 41.34 & (1.2\%) \\
\hline 16 & 740 & 66 & 5 & 60.66 & $(3.4 \%)$ & 66 & 3 & 40.44 & $(0.3 \%)$ \\
\hline 17 & 735 & 66 & 3 & 63.46 & $(2.2 \%)$ & 66 & 2 & 40.86 & $(2.4 \%)$ \\
\hline 18 & 740 & 66 & 4 & 54.81 & $(2.7 \%)$ & 66 & 2 & 35.97 & (8.8\%) \\
\hline 19 & 745 & 66 & 4 & 64.83 & $(2.3 \%)$ & 66 & 2 & 42.20 & $(2.6 \%)$ \\
\hline
\end{tabular}

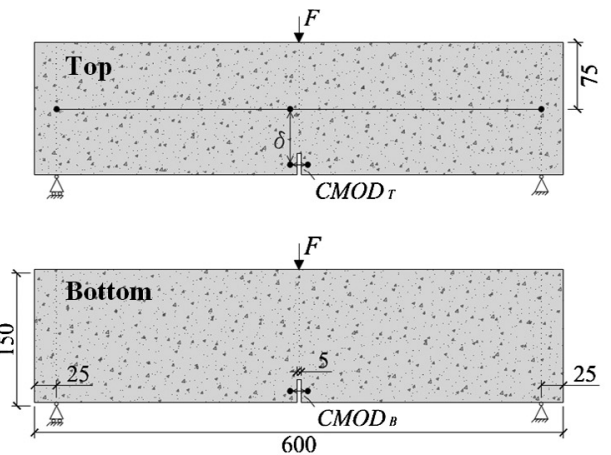

(a)

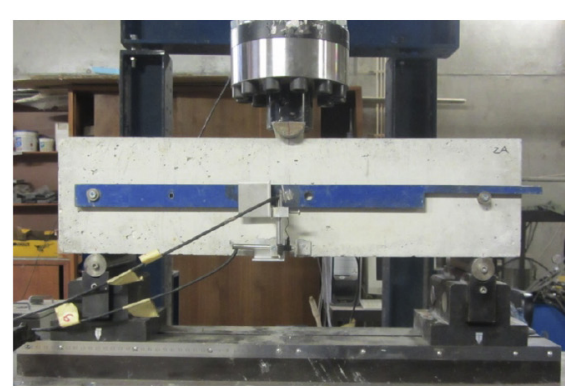

(b)

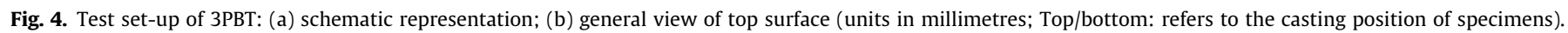

\subsection{Splitting test}

For the splitting tests, only the SFRSCC from casting 16 was considered (see Table 2). The specimens used in this study were obtained by drilling from a flat plate (laboratory prototype) and from a full-scale sandwich wall panel developed by the authors in the context of the LEGOUSE applied research project $[55,56]$. The tests carried out in specimens extracted from these elements will therefore allow to take conclusions about the flow induced orientation and dispersion of fibres on the post-cracking behaviour of this material.

The flat plate has the dimensions of $1.5 \times 1.0 \times 0.06 \mathrm{~m}^{3}$ and was casted with the SFRSCC feeding permanently at its central point (see Fig. 5a), letting the SFRSCC to flow radially until complete filling of the steel formwork. Abrishambaf et al. [17] have shown that for a plate with dimensions $1.5 \times 1.0 \times 0.06 \mathrm{~m}^{3}$, a uniform flow profile that diffuses outwards radially from the centre of the panel is achieved. This casting process was chosen since the high flowability of the developed SFRSCC suggests high probably of being adopted in several real applications. The sandwich wall panel (shown in Fig. 5) was poured in accordance with the procedures commonly adopted in the precast plant of the industrial partner, with the SFRSCC feeder moving along all the surface of the panel. The SFRSCC layer thickness of the sandwich panel from which the specimens were extracted was equal to the thickness of the flat plate, that is, $60 \mathrm{~mm}$. In both cases, no specimens were extracted from the vicinity of the edges of the formwork, as shown in Fig. 5, in order to reduce the interference of the wall effect from the lateral formwork on the results. The drilling operation was performed when the panels were already in their hardened-mature phase. In the flat plate the specimens were extracted from a distance of $300 \mathrm{~mm}$ and $600 \mathrm{~mm}$ from its centre (see Fig. 5a). In the sandwich panel, the specimens were extracted from the bottom layer of the panel, that was cast over the same steel surface used for casting the flat plate, thus keeping similar flowing conditions. As shown in Fig. 5b, the specimens of the sandwich panel were obtained from the lateral regions of its opening, in the region between the embedded Glass Fibre Reinforced Polymer (GFRP) connectors. These GFRP plate connectors were positioned perpendicularly to the surface of the SFRSCC layers and were embedded on these layers, as is described in Lameiras et al. [55]. Due to its flat nature and the relative proximity of these connectors, it is believed that, independently of the casting procedure, the SFRSCC had the tendency of flowing along the corridors formed by the connectors ( $y$-direction in Fig. $5 \mathrm{~b}$ ). In the $1.5 \times 1.0 \mathrm{~m}^{2}$ flat plate, the extracted specimens were submitted to a loading direction coincident with the notched plane executed in the specimen (Figs. 5 and 6). Since notched planes parallel and orthogonal to the flux lines of the SFRSCC were cut, the test results can provide information about the influence of the casting technology on the post-cracking behaviour of this material. With the same aim, the notched planes on the specimens extracted from the sandwich panel were cut in the $x$-direction and $y$-direction, since as already indicated, these are the critical directions in terms of fibre orientation and distribution. Before the drilling process, the positions and the notched planes of the specimens were marked, as shown in Fig. $5 \mathrm{c}$ and $\mathrm{d}$.

All the specimens had a diameter of $150 \mathrm{~mm}$. In terms of thickness, the specimens obtained from the $1.5 \times 1.0 \mathrm{~m}^{2}$ flat plate had a thickness that varied from 60.9 to $69.9 \mathrm{~mm}$, while in the sandwich wall panel, the thickness ranged from 50.2 to $63.1 \mathrm{~mm}$. This variation was probably a consequence of a non-perfectly flatness of the steel base of the formwork, and a certain lifting of polystyrene 


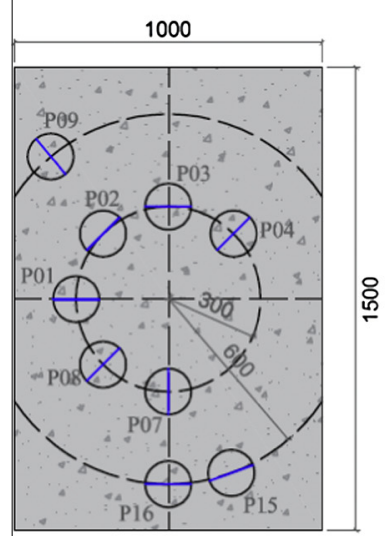

- Notch direction

(a)

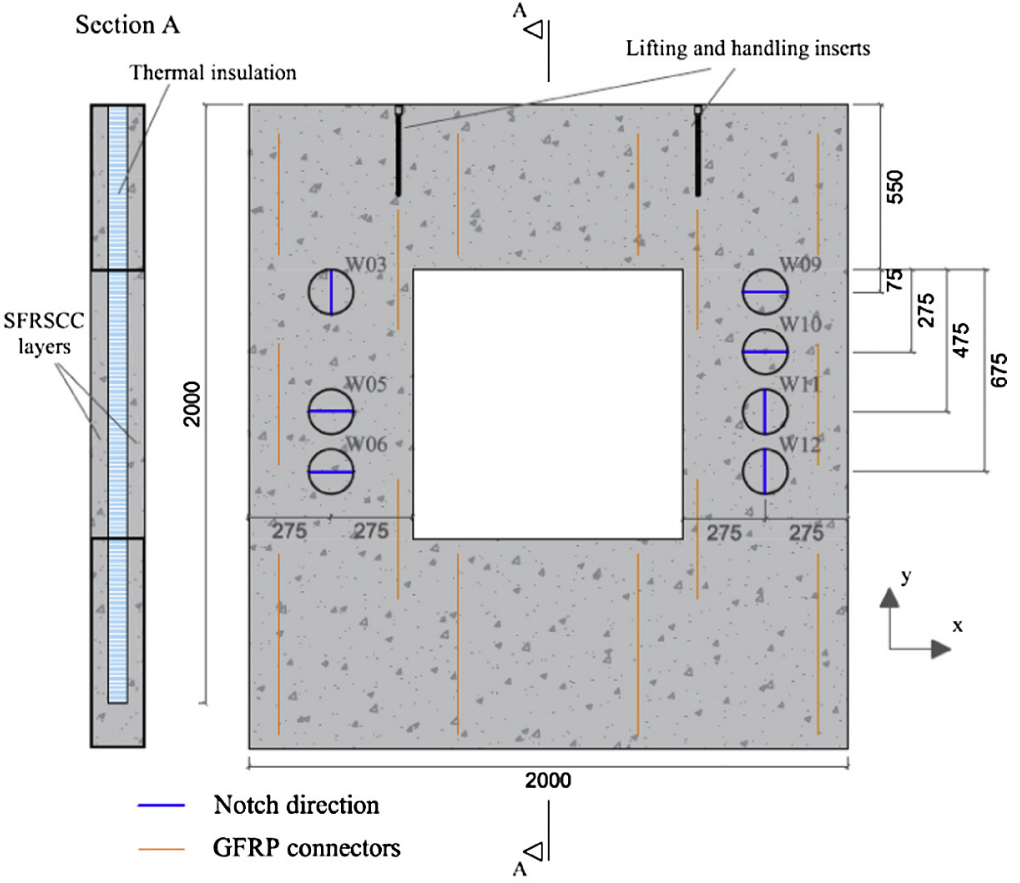

(b)

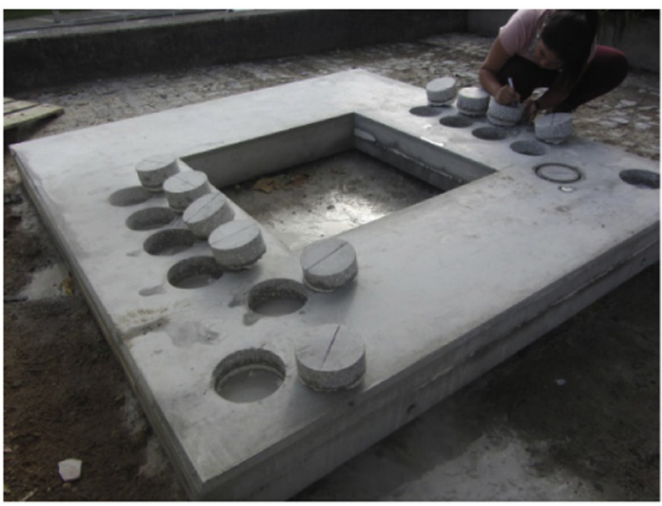

(d)

Fig. 5. Schematic representation of the specimens sawn out from: (a) flat plate; (b) sandwich panel. Overall view of the drilling process for: (c) flat plate; (d) sandwich panel (units in millimetres).

\section{Notch 1:}

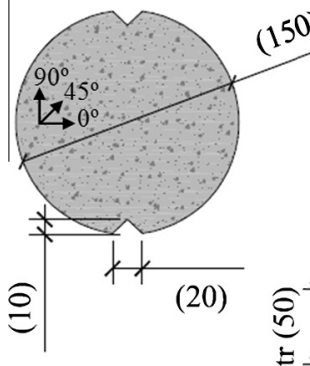

Notch 2:
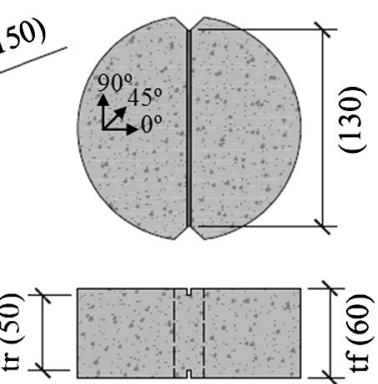

Notch 3:
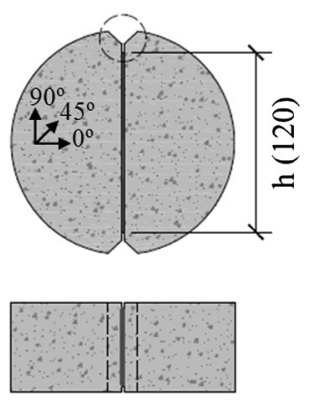

Detail:

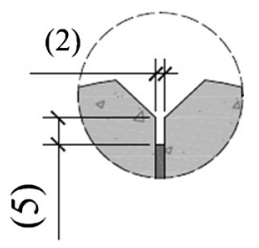

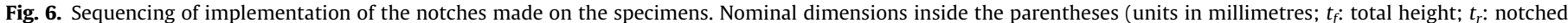
height).

foam during the casting process. Nine specimens were sawn out from the $1.5 \times 1.0 \mathrm{~m}^{2}$ flat plate, six at a distance of $300 \mathrm{~mm}$ and three of $600 \mathrm{~mm}$ from the centre of the plate. Among the specimens distanced $300 \mathrm{~mm}$ from the centre, four were used for tests with the load being applied parallel to the SFRSCC flux lines (P01, P04, P07 and P08), while the other two specimens were tested with the load being applied perpendicularly to the flux lines (P02 and P03). In the specimens obtained from a distance of $600 \mathrm{~mm}$ from 
the centre, only one specimen was tested with the load being applied parallel to the flow (P09), while the other two specimens were tested with the load applied perpendicular to the flux lines (P15 and P16).

As already indicated, one of the objectives of the present research was to improve the test setup proposed by Abrishambaf et al. [17] in order to determine, as directly as possible, the stress-crack width relationship that can be representative of the material behaviour in real structures. As reported in the cited work, the specimens used for the splitting tests are cylindrical, with a $150 \mathrm{~mm}$ diameter and have $5 \mathrm{~mm}$ deep notches parallel to the loading direction, in order to localize the specimen's fracture surface along the notched plane (see notch 2 in Fig. 6). Nonetheless, in the present research two additional notches were executed following the procedures adopted by di Prisco et al. [36]. In fact, in an attempt of inducing a stress field corresponding to an almost pure fracture mode I in the notched plane, a V-shaped groove with $45^{\circ}$ inclination has been cut at the extremities of the notched plane at the $+45^{\circ}$ and $-45^{\circ}$ directions, as illustrated in notch 1 of Fig. 6. The load is then applied by using steel rollers of $20 \mathrm{~mm}$ diameter that are accommodated into these grooves and directly pushed by the machine device, as shown in Fig. 7. This configuration aims to deviate the compressive stresses from the notched plane, creating, as much as possible, a uniaxial tensile stress field in the notched plane, orthogonal to this plane, as was done by di Prisco et al. [36]. Furthermore, following what was implemented by di Prisco et al. [36], two more $5 \mathrm{~mm}$ deep straight notches at the direction $90^{\circ}$ (see notch 3 in Fig. 6), originating from the vertices of the $\mathrm{V}$ grooves are executed to force the crack opening at the reduced section and to move the crack tip away from the load application zones, where high stress concentrations generally rise.
The test was conducted under displacement control of the piston of the load machine by using the following displacement rates: $1.0 \mu \mathrm{m} / \mathrm{s}$ up to the displacement of $2.0 \mathrm{~mm} ; 2 \mu \mathrm{m} / \mathrm{s}$ from $2.00 \mathrm{~mm}$ up to $3.0 \mathrm{~mm} ; 4 \mu \mathrm{m} / \mathrm{s}$ until the end of the test. For an accurate detection and tracking of the crack propagation, five LVDTs of $5 \mathrm{~mm}$ stroke were used to measure the crack opening displacement: three at the side of the specimen corresponding to the upper side during casting, and the two remaining at the other side of specimen (corresponding to the side in contact with the metallic formwork). The exact position of each LVDT is schematically represented in the Fig. 7d. The adopted disposition of the LVDTs allows the evaluation of the in-plane and out-of-plane rotation of the specimen in consequence of the fibre orientation and distribution in the notched plane. The load is registered by means of a $150 \mathrm{kN}$ load cell. All the splitting tests were carried out 56 days after casting.

\subsection{Assessment of the number of effective fibres}

After testing, each of the two faces of the fracture surface of a splitting tensile specimen was divided in four equal regions in order to evaluate the fibre distribution (see Fig. 8a -c). A similar procedure was adopted for the 3PBT specimens. However, for the 3PBT specimens, each of the two faces of the fracture surface was divided in nine regions as shown in Fig. 8d. The fibre distribution was evaluated by counting the number of effective fibres crossing the fractured surfaces (Fig. 8d). A fibre was considered effective when it was broken or when its visible length was, at least, two times larger than the length of the hooked part of fibre. Attention should be paid to the fact that this procedure for determining the number of effective fibres allows to draw conclusions about their orientation and distribution in the structural element.

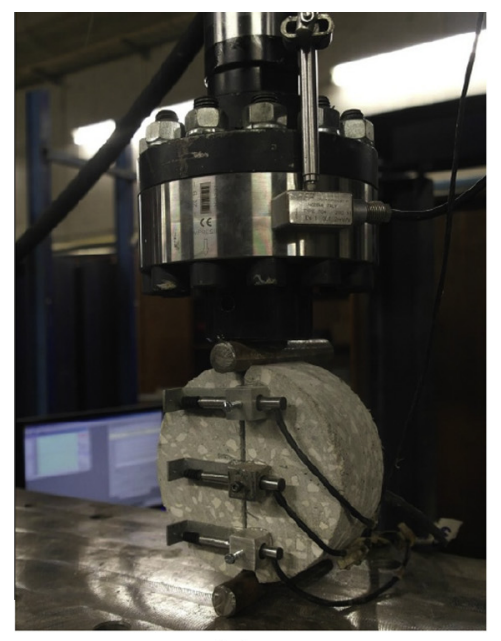

(a)

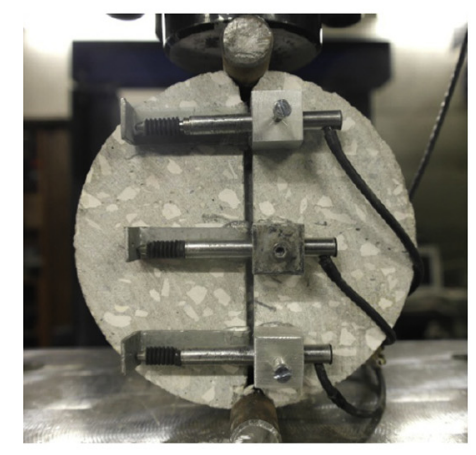

(b)

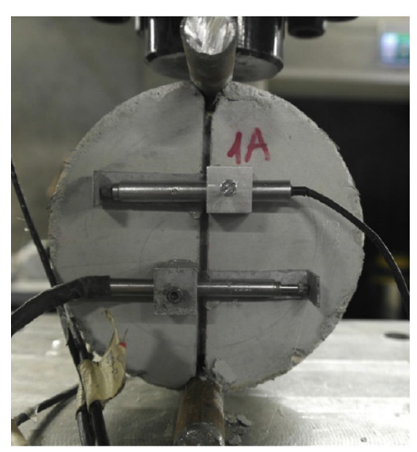

(c)

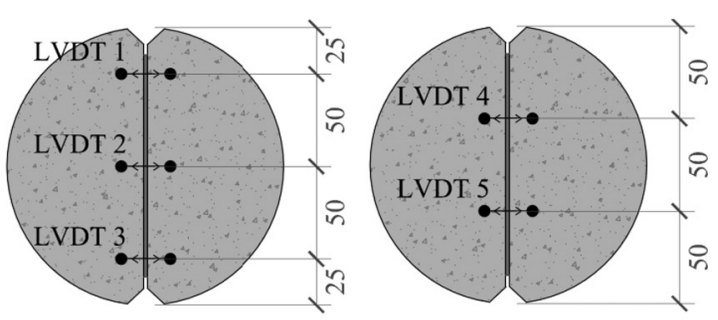

(d)

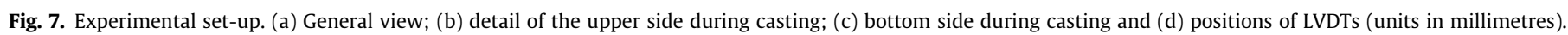




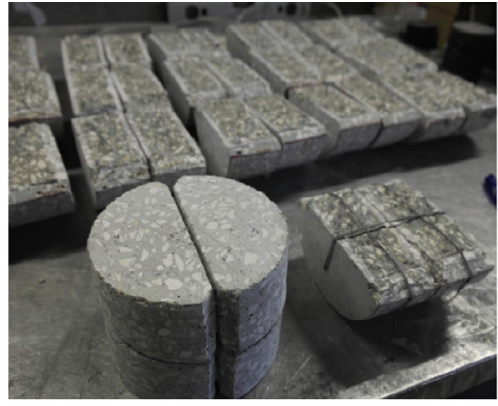

(a)

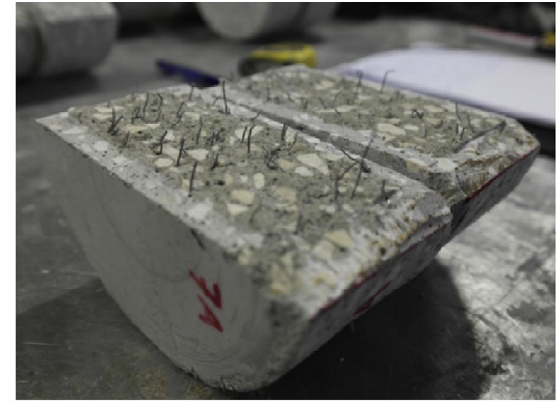

(b)

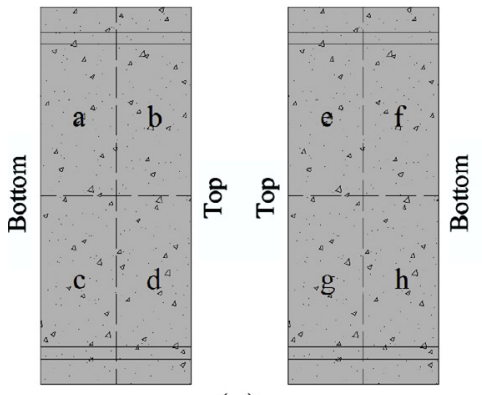

(c)

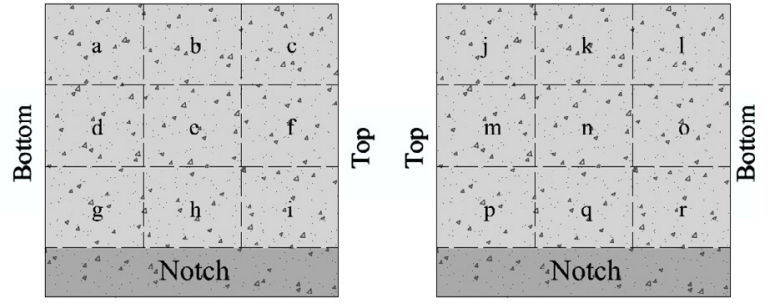

(d)

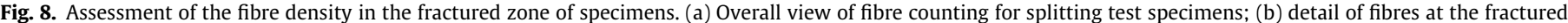

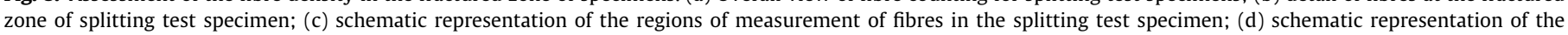
regions of measurement in the 3PBT specimen.

\section{Results and discussion}

\subsection{Three-point bending tests (3PBTs)}

For 27 out of the 40 specimens tested in 3PBT only one visible crack was formed in the notch plane. Nonetheless, due to the relatively high content of fibres, failures with multiple cracks concentrated in the midspan region of specimens were also observed (13/ 40 of specimens). For 11/40 of specimens the desirable fracture plane was not attained at all. Instead of that, an irregular surface fracture was observed because the crack tip deviated from the notched section However, for computing the equivalent and residual strengths all the tests were taken into account. The typical failure modes are depicted in Fig. 9a-c.

The average and envelope deflection versus CMOD relationship obtained for all the performed tests are presented in Fig. 10a. A relatively low dispersion of the results was obtained for this relationship. It was also verified that the average observed relationship fits very well the corresponding equation proposed by RILEM TC 162-TDF [20], which gives support on the reliability of this equation.

The average and the envelope load versus CMOD curves of these tests are depicted in Fig. 10b and a detailed view of the initial part of the experimental response is depicted on Fig. 10c. The curves corresponding to the upper bound (U.B.) and lower bound (L.B.) with a confidence level equal to $95 \%$ are also presented. Table 3 shows a summary of the strength parameters, presenting the average (Avg.), coefficient of variation ( $\mathrm{CoV}$ ) and the lower bound value (characteristic value) obtained for a confidence level of 95\% (L.B.95). The results are presented by separating the values obtained from different castings. From Table 3 it is verified that $f_{f c t, L}$ is similar for all the SFRSCC castings. This parameter is less affected by the fibre reinforcement and is mainly dependent on the matrix properties. Fig. 10b shows that the dispersion of results among specimens was significantly increased after crack initiation, since this testing stage is mainly governed by the fibre reinforcement mechanisms, whose effectiveness is dependent on the fibre orientation and distribution. This dispersion is also denoted in the $\mathrm{CoV}$ of the strength parameters that characterize the post-cracking behaviour of these composites, as noticeable in the values indicated in Table 3.

The results from the fibre counting, represented in Fig. 11, show that some fibre segregation has occurred. Due to higher density of steel, the fibres have tended to settle to the bottom part of the specimens. The observed relationships between the strength parameters $\left(f_{f c t, L} ; f_{R, 1} ; f_{R, 2} ; f_{R, 3} ; f_{R, 4} ; f_{e q, 2}\right.$ and $\left.f_{e q, 3}\right)$ and the average number of effective fibres per $\mathrm{cm}^{2}$ at the fracture surface of 3PBT's specimens are depicted in Fig. 12a-g.

Regarding the limit of proportionality $\left(f_{f c t, L}\right)$, as expected, no significant relation is observed with the number of effective fibres at the specimen's fracture surface. However, for the $f_{R}$ and $f_{\text {eq }}$ parameters, a clear tendency to increase, in an almost linear trend, with the number of effective fibres is visible. This behaviour was expected, since the stress transfer during the crack propagation is intimately related to the number of mobilized fibres. It is also possible to notice a tendency for decrease of the $R^{2}$ of the linear fit with the increase of the crack width at which the $f_{R}$ and $f_{e q}$ are evaluated, especially in the $f_{R}$, since as larger is the crack width as smaller is the effectiveness of the fibre reinforcement mechanisms of the adopted fibres. The $f_{e q}$ parameters are not so sensitive to this aspect, because $f_{e q}$ is obtained by considering the energy dissipated up to the crack with it corresponds, while $f_{R}$ parameters are determined by taking the load at the crack with it corresponds.

\subsection{Splitting tests}

Figs. 13 and 14 show the splitting tensile stress $\left(\sigma_{t, s p l i t}\right)$ versus crack width curves, where $\sigma_{t, \text { split }}$ is determined from the following equation:

$\sigma_{t, \text { split }}=\frac{2 \cdot P}{\pi \cdot t_{r} \cdot h}$ 


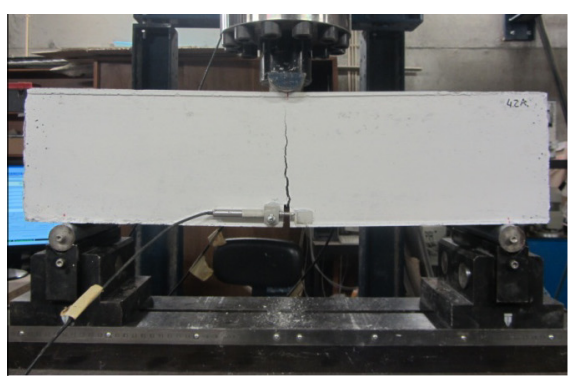

(a)

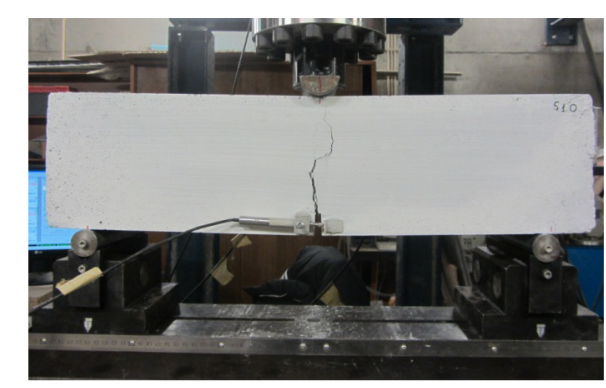

(c)

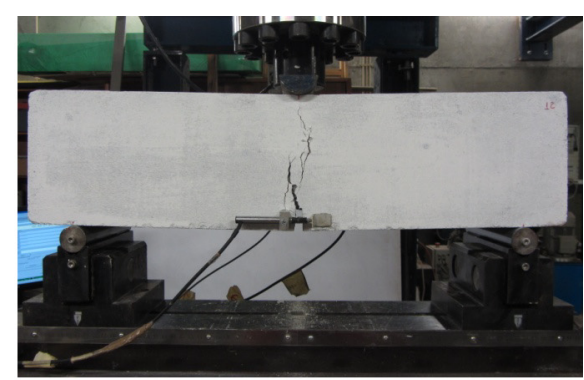

(b)

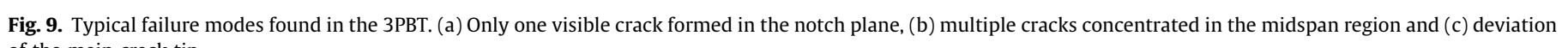
of the main crack tip.

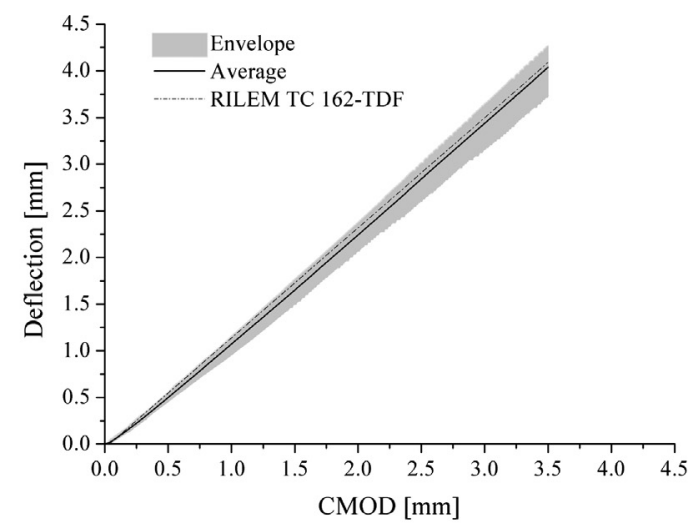

(a)

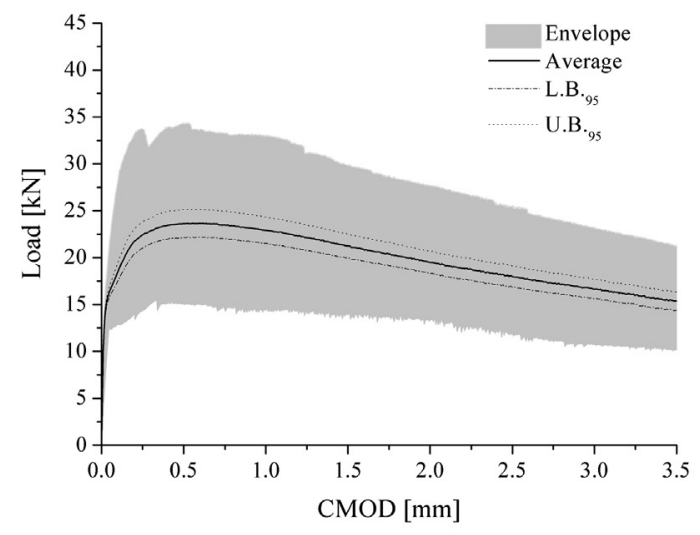

(b)

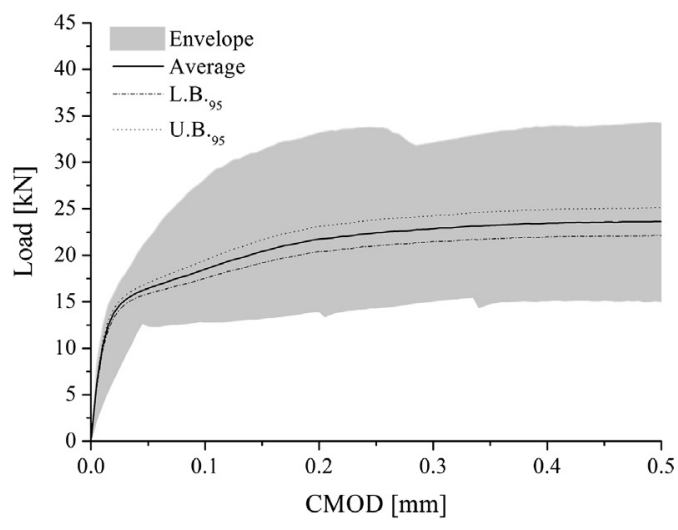

(c)

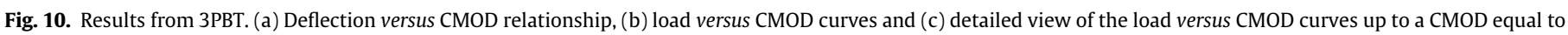
$0.5 \mathrm{~mm}$. 
Table 3

Average and characteristic post-cracking parameters for different castings of SFRSCC.

\begin{tabular}{|c|c|c|c|c|c|c|c|c|c|c|}
\hline \multicolumn{3}{|c|}{$\begin{array}{l}\text { Casting (number of } \\
\text { specimens) }\end{array}$} & \multirow[t]{2}{*}{$f_{f c t, L}(\mathrm{MPa})$} & \multirow[t]{2}{*}{$f_{c t}\left(0.7 * f_{f c t, L}\right)(\mathrm{MPa})$} & \multicolumn{2}{|c|}{$\begin{array}{l}\text { Equivalent flexural tensile } \\
\text { strength }\end{array}$} & \multicolumn{4}{|c|}{ Residual flexural tensile strength } \\
\hline & & & & & $f_{e q, 2}(\mathrm{MPa})$ & $f_{\text {eq,3 }}(\mathrm{MPa})$ & $f_{R, 1}(\mathrm{MPa})$ & $f_{R, 2}(\mathrm{MPa})$ & $f_{R, 3}(\mathrm{MPa})$ & $\overline{f_{R, 4}(\mathrm{MPa})}$ \\
\hline \multirow{5}{*}{10} & \multirow{5}{*}{$(5)$} & Avg. & 5.8 & 4.06 & 9.62 & 8.1 & 9.21 & 8.11 & 6.82 & 5.7 \\
\hline & & $\mathrm{CoV}$ & $13.30 \%$ & $13.30 \%$ & $12.40 \%$ & $15.00 \%$ & $13.80 \%$ & $15.40 \%$ & $15.70 \%$ & $18.50 \%$ \\
\hline & & L.B.*95 & 5.13 & 3.59 & 8.57 & 7.03 & 8.1 & 7.02 & 5.88 & 4.77 \\
\hline & & Avg. & 5.25 & 3.67 & 8.46 & 7.21 & 8.22 & 7.13 & 5.42 & 4.13 \\
\hline & & $\mathrm{CoV}$ & $0.90 \%$ & $0.90 \%$ & $4.50 \%$ & $0.80 \%$ & $4.20 \%$ & $2.70 \%$ & $10.70 \%$ & $19.40 \%$ \\
\hline \multirow[t]{3}{*}{11} & $(3)$ & L.B. 95 & 5.2 & 3.64 & 8.03 & 7.15 & 7.82 & 6.91 & 4.76 & 3.22 \\
\hline & & Avg. & 5.11 & 3.58 & 7.63 & 6.57 & 7.44 & 6.77 & 5.52 & 4.61 \\
\hline & & $\mathrm{CoV}$ & $13.20 \%$ & $13.20 \%$ & $26.80 \%$ & $26.40 \%$ & $27.20 \%$ & $24.60 \%$ & $28.60 \%$ & $26.30 \%$ \\
\hline \multirow[t]{3}{*}{12} & $(7)$ & L.B. ${ }^{*}{ }^{2}$ & 4.61 & 3.23 & 6.12 & 5.28 & 5.94 & 5.54 & 4.35 & 3.72 \\
\hline & & Avg. & 5.23 & 3.66 & 6.98 & 6.12 & 6.82 & 6.25 & 5.38 & 4.69 \\
\hline & & $\mathrm{CoV}$ & $8.50 \%$ & $8.50 \%$ & $18.90 \%$ & $19.20 \%$ & $41.40 \%$ & $20.70 \%$ & $22.20 \%$ & $22.50 \%$ \\
\hline \multirow[t]{3}{*}{13} & $(5)$ & L.B.* 95 & 4.84 & 3.39 & 5.82 & 5.09 & 5.69 & 5.2 & 4.46 & 3.9 \\
\hline & & Avg. & 5.09 & 3.56 & 6.87 & 5.92 & 6.67 & 5.97 & 5.26 & 4.54 \\
\hline & & $\mathrm{CoV}$ & $17.50 \%$ & $17.50 \%$ & $29.00 \%$ & $28.50 \%$ & $29.70 \%$ & $27.80 \%$ & $27.60 \%$ & $25.50 \%$ \\
\hline \multirow[t]{3}{*}{16} & $(5)$ & L.B. 95 & 4.31 & 3.02 & 5.12 & 4.44 & 4.93 & 4.51 & 3.98 & 3.53 \\
\hline & & Avg. & 5.54 & 3.88 & 8.64 & 7.51 & 8.39 & 7.59 & 6.52 & 5.66 \\
\hline & & $\mathrm{CoV}$ & $8.40 \%$ & $8.40 \%$ & $7.40 \%$ & $8.30 \%$ & $7.20 \%$ & $8.30 \%$ & $11.00 \%$ & $12.00 \%$ \\
\hline \multirow[t]{3}{*}{17} & $(5)$ & L.B. 95 & 5.13 & 3.59 & 8.08 & 6.96 & 7.86 & 7.04 & 5.89 & 5.06 \\
\hline & & Avg. & 5.63 & 3.94 & 8.55 & 7.38 & 8.36 & 7.47 & 6.4 & 5.59 \\
\hline & & $\mathrm{CoV}$ & $7.90 \%$ & $7.90 \%$ & $7.50 \%$ & $7.30 \%$ & $7.40 \%$ & $7.20 \%$ & $9.60 \%$ & $11.40 \%$ \\
\hline \multirow[t]{3}{*}{18} & (5) & L.B. ${ }^{*}$ & 5.24 & 3.67 & 7.39 & 6.35 & 7.22 & 6.42 & 5.47 & 4.8 \\
\hline & & Avg. & 4.91 & 3.66 & 6.9 & 5.87 & 6.62 & 6.01 & 5.16 & 4.55 \\
\hline & & $\mathrm{CoV}$ & $10.90 \%$ & $7.00 \%$ & $15.60 \%$ & $13.70 \%$ & $16.00 \%$ & $13.70 \%$ & $12.60 \%$ & $13.70 \%$ \\
\hline 19 & $(5)$ & L.B. ${ }^{*}$ & 4.44 & 3.34 & 5.96 & 5.17 & 5.69 & 5.29 & 4.59 & 4.01 \\
\hline
\end{tabular}

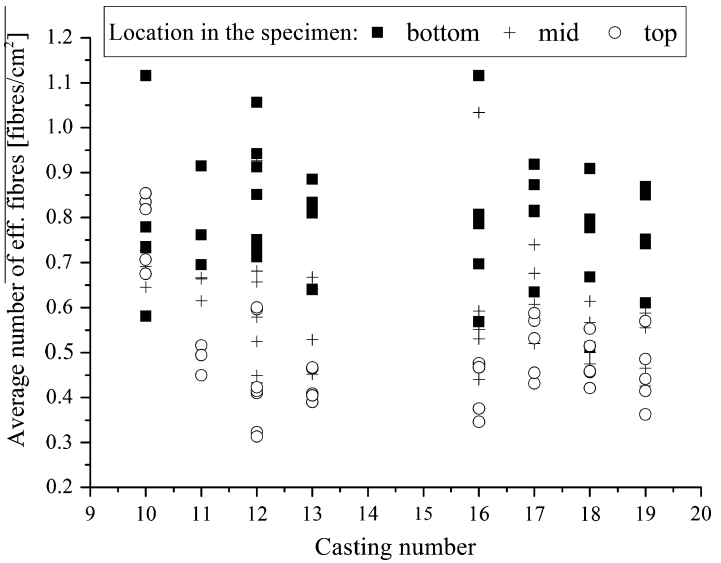

Fig. 11. Fibre distribution at the cross section of the 3PBT's specimens.

where $P$ is the compressive load applied in the specimen, $t_{r}$ is the height of the SFRSCC cylinder and $h$ is the diameter of the remaining SFRSCC cylinder after the notches are executed in the specimen, as shown in Fig. 6. The nominal values for $t_{r}$ and $h$ are equal to 50 and $120 \mathrm{~mm}$, respectively.

The crack width of the abscissa axes of Figs. 13 and 14 corresponds to the average of the values measured in the five LVDTs installed in the splitting tensile specimen (Fig. 7). The average, envelope and Lower Bound (L.B.) and Upper Bound (U.B.) characteristics curves corresponding to a confidence level $(k)$ equal to 95\% are also presented in Figs. 13 and 14. The questionability of using Eq. (6) for the characterization of the tensile stress on the post-peak phase of splitting tensile tests is conceptually the same as that of using the theory of elasticity for the evaluation of the $f_{R}$ and $f_{e q}$ for flexural tests, as recommended by RILEM TC 162TDF [46].

As already shown by Ferrara et al. [11], and di Prisco et al. [36], the local dispersion and orientation of fibres are responsible for the obtained experimental scattering in stress-crack width curves. Despite the high dispersion of the results observed in specimens collected from the $1.5 \times 1.0 \mathrm{~m}^{2}$ panel (see Fig. 13), it is quite evident that the stress at crack initiation, and mainly the post-cracking tensile strength, were higher in the specimens loaded in the direction of the SFRSCC flux lines than in the orthogonal direction, since, as already demonstrated by Abrishambaf et al. [17], the fibres have the tendency to orientate orthogonally to the SFRSCC flux lines.

The same tendency was observed in the specimens obtained from the sandwich panel (Fig. 14). As already indicated, due to the procedures adopted for casting and considering the geometry of panel, the SFRSCC has preferentially flowed along the $y$-direction in the left and right sides of the opening. This fact explains the similarities between the experimental responses in Fig. 13a and b, corresponding to specimens loaded in a direction parallel to the SFRSCC flux lines. Similar arguments explain the similarity of the experimental responses obtained in the specimens with the loading direction perpendicular to the SFRSCC flux lines (Fig. 13b) and in the specimens cored from the sandwich panels with the loading direction parallel to the $x$-direction (Fig. 14a).

In the specimens tested with loading direction parallel to the SFRSCC flux lines (Figs. 13a and 14b), it is noticeable that upon crack initiation there is a small load decay followed by slight strain-hardening branch, whereas in the specimens with loading direction perpendicular to the SFRSCC flux lines, after the first crack, only a strain-softening branch is verified.

The relevant conclusions taken from the stress versus crack opening relationships can be also confirmed by determining the residual strength parameters $\left(\sigma_{w_{*}}\right)$ and the energy absorption during the fracture process $\left(G_{F W *}\right)$, whose values are presented in Tables 4-7. It is noted that the value attributed to the subscript " $W *$ " represents the crack width at which $\sigma_{w}$ and $G_{F}$ are evaluated.

The above mentioned preferential alignment of fibres are corroborated by the results of effective fibre counting at the fractured surface of splitting specimen, shown in Tables 8 and 9 for the 


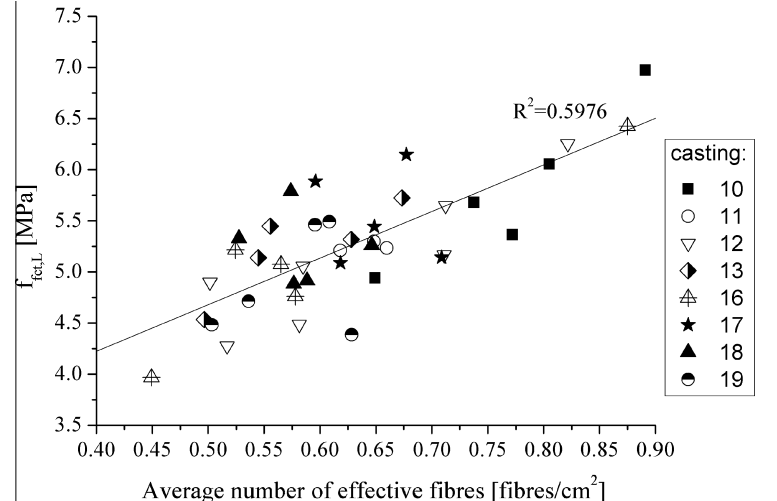

(a)

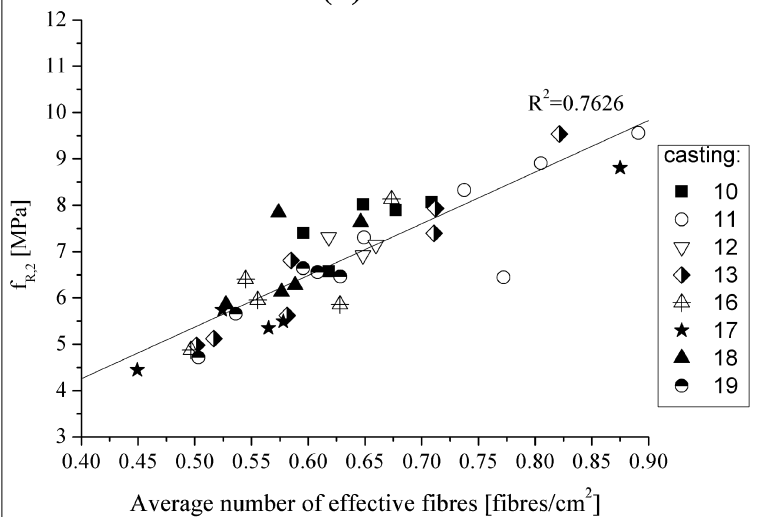

(c)

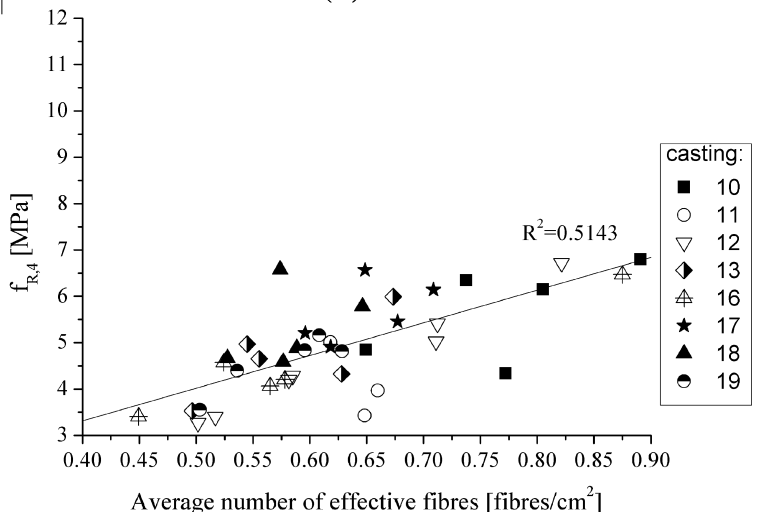

(e)

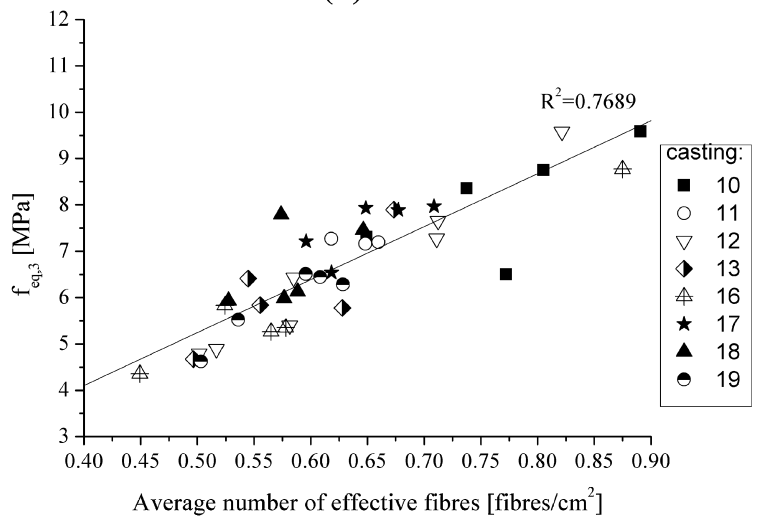

(g)

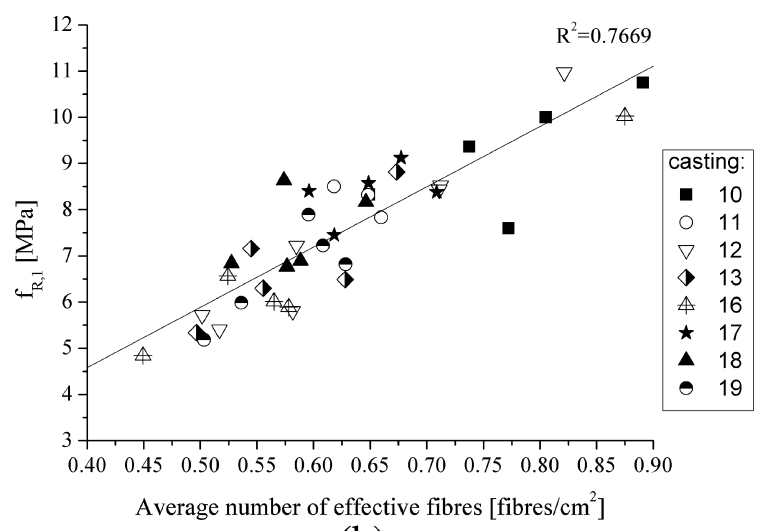

(b)

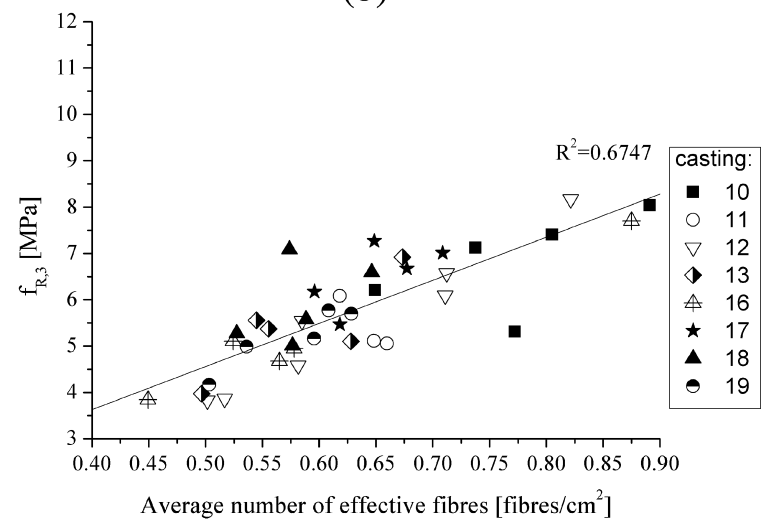

(d)

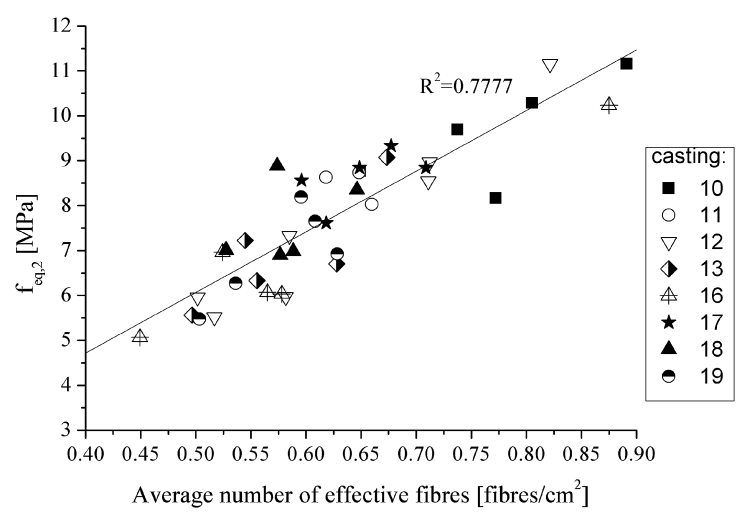

(f) 


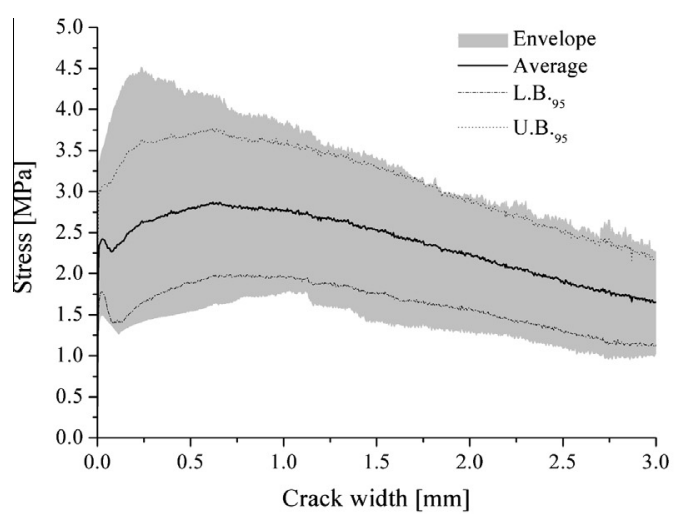

(a)

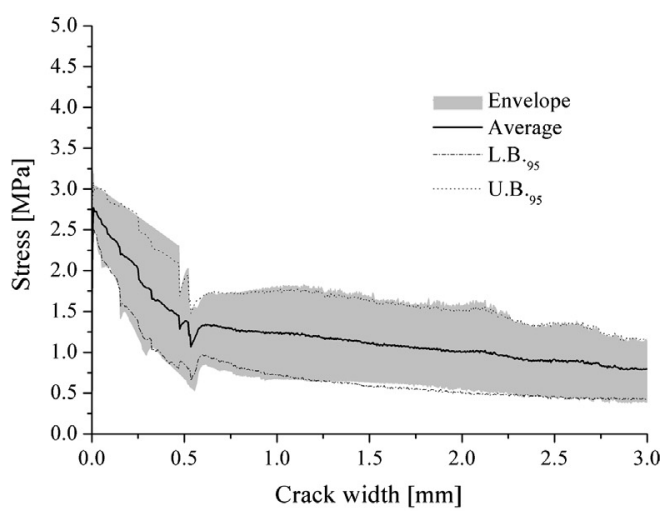

(b)

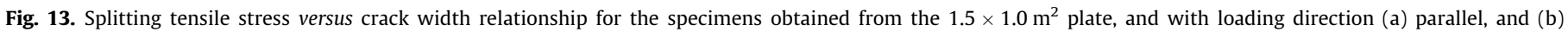
perpendicular, to the SFRSCC flux lines.

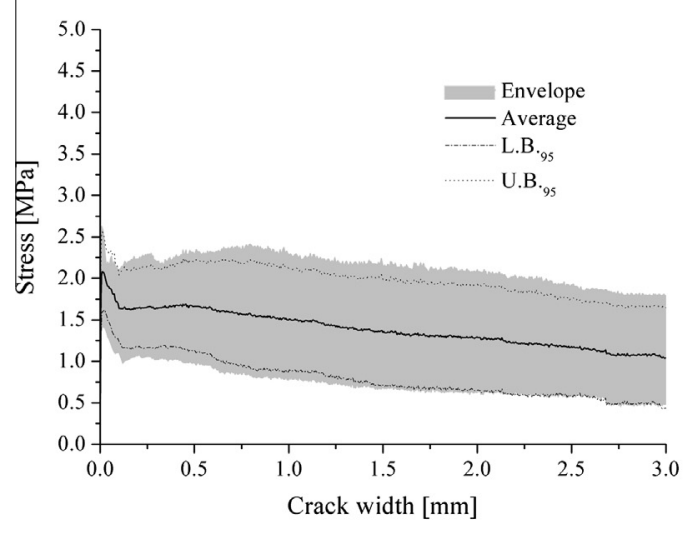

(a)

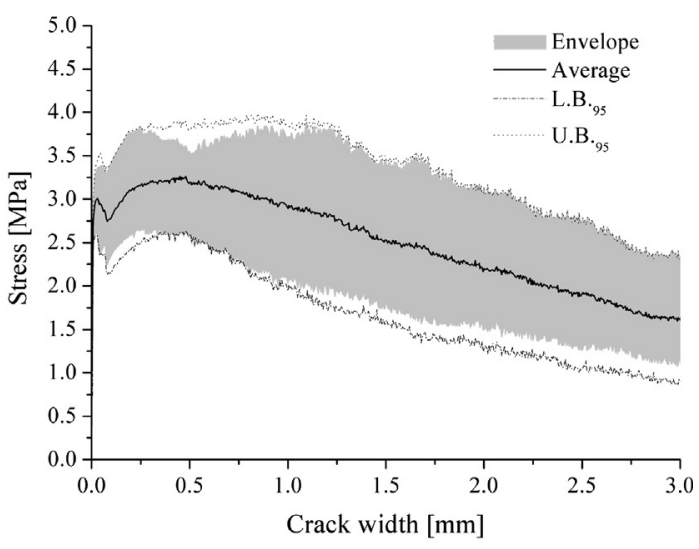

(b)

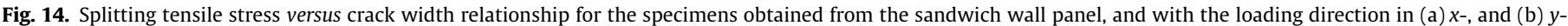
direction.

specimens obtained from the $1.5 \times 1.0 \mathrm{~m}^{2}$ plate and from the sandwich wall panels, respectively. The values presented in the Tables 8 and 9 highlight the correlation between the post-cracking response of specimens and the effective fibre counting at the fractured specimens. Moreover, when the data in Table 8 corresponding to the $1.5 \times 1.0 \mathrm{~m}^{2}$ plate are evaluated separately by load direction, it is verified that the average number of effective fibres in the specimens loaded parallel to the SFRSCC flux lines is twice the average number of fibres counted in the specimens with the load applied perpendicularly to the SFRSCC flux lines. For the sandwich wall panel (see Table 9) the ratio of the average number of fibres counted in the specimens with load applied parallel to the $y$-direction versus $x$-direction is 1.4 , which is not as high as the value observed in the other panel due to the distinct flux conditions in the two types of panels. Furthermore, when the data contained in Table 8 is separated according to the distance of the specimens from the centre of the panel, the tendency of having higher number of effective fibres in the proximity of point from where the mould was fed by SFRSCC can be confirmed. The average number of effective fibres in the specimens collected nearer the centre of the plate was $13 \%$ higher for the specimens with the load applied parallel to the concrete flow. This percentage was $64 \%$ for the specimens with the load applied perpendicular to the concrete flow. Nonetheless, although the results obtained with the splitting tests seem consistent with this information, quantitative conclusions cannot be issued due to the relatively small number of tested specimens.
The results obtained in the specimens drilled from $1.5 \times 1.0 \mathrm{~m}^{2}$ plate and from the sandwich panel are in accordance to the data presented by Abrishambaf et al. [17] and di Prisco et al. [36], since higher post-cracking parameters were obtained in the specimens with the fracture plane parallel to the SFRC flow direction. In these mentioned works, the difference of residual strengths was ascribed to a preferential fibre alignment influenced by the SFRC's flow, in accordance to the observations of the current research work.

The results obtained by the splitting tests indicate that the properties are too affected by the fibre orientation caused by the concrete flow conditions and geometric characteristics of the casted structural element. Thus, the aforementioned observations reinforce the remark of di Prisco et al. [32] that, for the characterization of the FRC used in structural elements, there is a need to use specimens that can reproduce the real fibre reinforcement mechanisms of the actual structural element. This is particularly important in the case of elements with reduced thickness (slender slab-like type elements), where the "wall effect" gives to the FRC a pronounced orthotropic and even anisotropic behaviour that should be properly captured for a correct design. Furthermore, the results obtained in this work reiterate that, for the FRC with self-compacting properties, it is also necessary to take into account its flow characteristics and the casting procedure. The authors believe that the method employed in this work, which consists in casting a plate with the same thickness of the structural element, and applying a casting methodology similar to the one adopted 
Table 4

Maximum stress, residual stress and dissipated energy for the specimens extracted from $1.5 \times 1.0 \mathrm{~m}^{2}$ plate and with load applied parallel to the SFRSCC flux lines.

\begin{tabular}{|c|c|c|c|c|c|c|c|c|c|c|c|}
\hline Specimen & $\sigma_{\max }(\mathrm{MPa})$ & $\sigma_{0.3}(\mathrm{MPa})$ & $\sigma_{0.5}(\mathrm{MPa})$ & $\sigma_{1.0}(\mathrm{MPa})$ & $\sigma_{1.5}(\mathrm{MPa})$ & $\sigma_{3.0}(\mathrm{MPa})$ & $G_{F 0.3}(\mathrm{~N} / \mathrm{mm})$ & $G_{F 0.5}(\mathrm{~N} / \mathrm{mm})$ & $G_{F 1.0}(\mathrm{~N} / \mathrm{mm})$ & $G_{F 1.5}(\mathrm{~N} / \mathrm{mm})$ & $G_{F 3.0}(\mathrm{~N} / \mathrm{mm})$ \\
\hline P01 & 4.66 & 4.38 & 4.18 & 3.78 & 3.42 & 2.26 & 1.24 & 2.10 & 4.10 & 5.89 & 9.97 \\
\hline P04 & 3.20 & 2.31 & 2.25 & 1.91 & 1.44 & 1.04 & 0.71 & 1.17 & 2.22 & 3.03 & 4.83 \\
\hline P07 & 3.06 & 2.34 & 2.57 & 2.83 & 2.87 & 1.63 & 0.63 & 1.13 & 2.48 & 3.84 & 7.30 \\
\hline P08 & 3.75 & 2.78 & 3.43 & 3.53 & 3.14 & 2.25 & 0.68 & 1.31 & 3.09 & 4.78 & 8.94 \\
\hline P09 & 1.87 & 1.46 & 1.55 & 1.78 & 1.79 & 1.07 & 0.42 & 0.72 & 1.55 & 2.45 & 4.56 \\
\hline Average & 3.31 & 2.65 & 2.80 & 2.76 & 2.53 & 1.65 & 0.74 & 1.28 & 2.69 & 4.00 & 7.12 \\
\hline $\mathrm{CoV}$ & $31 \%$ & $41 \%$ & $37 \%$ & $33 \%$ & $34 \%$ & $37 \%$ & $41 \%$ & $39 \%$ & $36 \%$ & $34 \%$ & $34 \%$ \\
\hline
\end{tabular}

Table 5

Maximum stress, residual stress and dissipated energy for the specimens extracted from $1.5 \times 1.0 \mathrm{~m}^{2}$ plate and with load applied perpendicular to the SFRSCC flux lines.

\begin{tabular}{|c|c|c|c|c|c|c|c|c|c|c|c|}
\hline Specimen & $\sigma_{\max }(\mathrm{MPa})$ & $\sigma_{0.3}(\mathrm{MPa})$ & $\sigma_{0.5}(\mathrm{MPa})$ & $\sigma_{1.0}(\mathrm{MPa})$ & $\sigma_{1.5}(\mathrm{MPa})$ & $\sigma_{3.0}(\mathrm{MPa})$ & $G_{F 0.3}(\mathrm{~N} / \mathrm{mm})$ & $G_{F 0.5}(\mathrm{~N} / \mathrm{mm})$ & $G_{F 1.0}(\mathrm{~N} / \mathrm{mm})$ & $G_{F 1.5}(\mathrm{~N} / \mathrm{mm})$ & $G_{F 3.0}(\mathrm{~N} / \mathrm{mm})$ \\
\hline P02 & 3.49 & 1.81 & 1.31 & 0.94 & 0.66 & 0.39 & 0.33 & 0.60 & 1.15 & 1.54 & 2.30 \\
\hline P03 & 2.71 & 1.75 & 1.58 & 1.56 & 1.48 & 1.13 & 0.59 & 0.92 & 1.70 & 2.47 & 4.41 \\
\hline P15 & 3.04 & 2.58 & 1.93 & 1.81 & 1.66 & 1.12 & 0.83 & 1.30 & 2.15 & 3.03 & 5.15 \\
\hline P16 & 3.09 & 1.01 & 0.68 & 0.68 & 0.64 & 0.55 & 0.52 & 0.70 & 1.06 & 1.39 & 2.26 \\
\hline Average & 3.08 & 1.78 & 1.37 & 1.25 & 1.11 & 0.80 & 0.57 & 0.88 & 1.52 & 2.11 & 3.53 \\
\hline $\mathrm{CoV}$ & $10 \%$ & $36 \%$ & $38 \%$ & $42 \%$ & $48 \%$ & $48 \%$ & $37 \%$ & $36 \%$ & $34 \%$ & $37 \%$ & $42 \%$ \\
\hline
\end{tabular}

Table 6

Maximum stress, residual stress and dissipated energy for the specimens extracted from sandwich wall panel and with load applied parallel to the $x$-direction.

\begin{tabular}{|c|c|c|c|c|c|c|c|c|c|c|c|}
\hline Specimen & $\sigma_{\max }(\mathrm{MPa})$ & $\sigma_{0.3}(\mathrm{MPa})$ & $\sigma_{0.5}(\mathrm{MPa})$ & $\sigma_{1.0}(\mathrm{MPa})$ & $\sigma_{1.5}(\mathrm{MPa})$ & $\sigma_{3.0}(\mathrm{MPa})$ & $G_{F 0.3}(\mathrm{~N} \mathrm{~mm})$ & $G_{F 0.5}(\mathrm{~N} \mathrm{~mm})$ & $G_{F 1.0}(\mathrm{~N} \mathrm{~mm})$ & $G_{F 1.5}(\mathrm{~N} \mathrm{~mm})$ & $G_{F 3.0}(\mathrm{~N} \mathrm{~mm})$ \\
\hline W05 & 1.81 & 1.02 & 0.98 & 0.78 & 0.69 & 0.49 & 0.33 & 0.53 & 0.96 & 1.33 & 2.22 \\
\hline W06 & 2.74 & 1.62 & 1.60 & 1.28 & 0.97 & 0.58 & 0.52 & 0.84 & 1.53 & 2.59 & 3.38 \\
\hline W09 & 2.23 & 1.73 & 1.80 & 1.65 & 1.60 & 1.30 & 0.54 & 0.90 & 1.76 & 2.57 & 4.72 \\
\hline W10 & 2.69 & 2.21 & 2.29 & 2.29 & 2.14 & 1.79 & 0.66 & 1.11 & 2.28 & 3.39 & 6.36 \\
\hline Average & 2.37 & 1.65 & 1.67 & 1.50 & 1.35 & 1.04 & 0.51 & 0.85 & 1.63 & 2.47 & 4.17 \\
\hline $\mathrm{CoV}$ & $19 \%$ & $30 \%$ & $32 \%$ & $42 \%$ & $48 \%$ & $59 \%$ & $26 \%$ & $28 \%$ & $33 \%$ & $34 \%$ & $43 \%$ \\
\hline
\end{tabular}

Table 7

Maximum stress, residual stress and dissipated energy for the specimens extracted from sandwich wall panel and with load applied parallel to the $y$-direction.

\begin{tabular}{|c|c|c|c|c|c|c|c|c|c|c|c|}
\hline Specimen & $\sigma_{\max }(\mathrm{MPa})$ & $\sigma_{0.3}(\mathrm{MPa})$ & $\sigma_{0.5}(\mathrm{MPa})$ & $\sigma_{1.0}(\mathrm{MPa})$ & $\sigma_{1.5}(\mathrm{MPa})$ & $\sigma_{3.0}(\mathrm{MPa})$ & $G_{F 0.3}(\mathrm{~N} \mathrm{~mm})$ & $G_{F 0.5}(\mathrm{~N} \mathrm{~mm})$ & $G_{F 1.0}(\mathrm{~N} \mathrm{~mm})$ & $G_{F 1.5}(\mathrm{~N} \mathrm{~mm})$ & $G_{F 3.0}(\mathrm{~N} \mathrm{~mm})$ \\
\hline W03 & 3.93 & 3.79 & 3.54 & 2.94 & 2.35 & 1.41 & 1.07 & 1.80 & 3.41 & 4.73 & 7.50 \\
\hline W11 & 2.76 & 2.62 & 2.59 & 2.03 & 1.81 & 1.14 & 0.75 & 1.27 & 2.42 & 3.39 & 5.52 \\
\hline W12 & 4.03 & 3.20 & 3.45 & 3.71 & 3.44 & 2.34 & 0.86 & 1.54 & 3.39 & 5.22 & 9.55 \\
\hline Average & 3.57 & 3.21 & 3.19 & 2.89 & 2.53 & 1.63 & 0.89 & 1.54 & 3.07 & 4.44 & 7.52 \\
\hline $\mathrm{CoV}$ & $20 \%$ & $18 \%$ & $17 \%$ & $29 \%$ & $33 \%$ & $38 \%$ & $18 \%$ & $17 \%$ & $18 \%$ & $21 \%$ & $27 \%$ \\
\hline
\end{tabular}

Table 8

Fibre counting at fractured surface of specimens extracted from $1.5 \times 1.0 \mathrm{~m}^{2}$ plate

\begin{tabular}{|c|c|c|c|c|c|c|c|}
\hline \multirow[t]{3}{*}{ Loading direction } & \multirow[t]{3}{*}{ Distance from centre $(\mathrm{mm})$} & \multirow[t]{3}{*}{ Specimen } & \multicolumn{5}{|c|}{ Average number of fibres (fibres $/ \mathrm{cm}^{2}$ ) } \\
\hline & & & \multicolumn{3}{|c|}{ Per specimen } & \multicolumn{2}{|l|}{ Summary } \\
\hline & & & Bottom & Top & Total & Per load direction & Per distance from centre \\
\hline \multirow[t]{5}{*}{ Parallel to flow } & 300 & P01 & 0.87 & 0.65 & 0.76 & \multirow[t]{5}{*}{0.66} & 0.67 \\
\hline & 300 & P04 & 0.61 & 0.54 & 0.57 & & \\
\hline & 300 & P07 & 0.64 & 0.72 & 0.68 & & \\
\hline & 300 & P08 & 0.78 & 0.58 & 0.68 & & \\
\hline & 600 & P09 & 0.62 & 0.56 & 0.59 & & 0.59 \\
\hline \multirow[t]{4}{*}{ Perpendicular to flow } & 300 & P02 & 0.34 & 0.29 & 0.31 & \multirow[t]{4}{*}{0.33} & 0.41 \\
\hline & 300 & $\mathrm{P} 03$ & 0.57 & 0.43 & 0.50 & & \\
\hline & 600 & P15 & 0.37 & 0.21 & 0.29 & & 0.25 \\
\hline & 600 & P16 & 0.16 & 0.27 & 0.22 & & \\
\hline
\end{tabular}

in the corresponding real application, is a promising procedure to determine the values of the fracture parameters of SFRSCC to be assumed in the design of the actual structural element. In this context, the residual strength could be defined by considering the results of tests performed with specimens extracted from different distances from the feeding point, perpendicularly and parallel to the concrete flow, as was done in this work. By knowing the fibre orientation and distribution, different constitutive laws for the fracture process can be attributed to each representative volume by considering the crack orientation towards the governing fibre orientation, under the framework of the FEM-based material nonlinear approaches. 
Table 9

Fibre counting at fractured surface of specimens extracted from the sandwich wall panel.

\begin{tabular}{llllll}
\hline Loading direction & Specimen & \multicolumn{2}{l}{$\begin{array}{l}\text { Average number of effective fibres (fibres/ } \\
\mathrm{cm}^{2} \text { ) }\end{array}$} & Summary per direction \\
\cline { 3 - 5 } & & \multicolumn{3}{l}{ Per specimen } & \\
\cline { 3 - 5 } & & Bottom & Top & Total & \\
\hline \multirow{2}{*}{$x$} & W05 & 0.42 & 0.16 & 0.29 & 0.54 \\
& W06 & 0.44 & 0.54 & 0.49 & \\
& W09 & 0.74 & 0.68 & 0.71 & \\
W10 & 0.50 & 0.86 & 0.68 & \\
$y$ & W03 & 0.60 & 0.84 & 0.72 & 0.77 \\
& W11 & 0.70 & 0.60 & 0.65 & \\
& W12 & 1.05 & 0.83 & 0.94 & \\
\hline
\end{tabular}

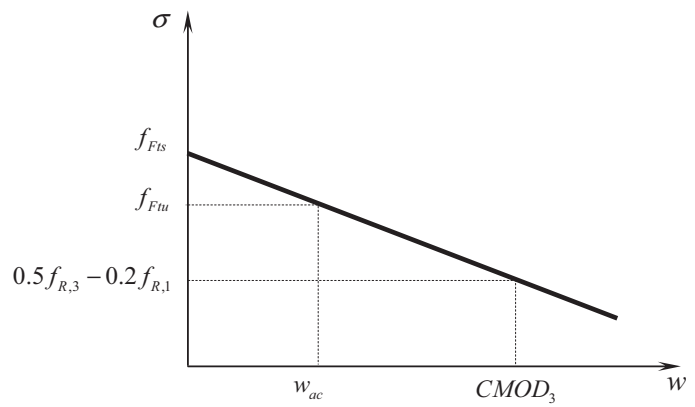

Fig. 15. Stress-crack width constitutive law proposed by fib MC $2010[44,45]$.

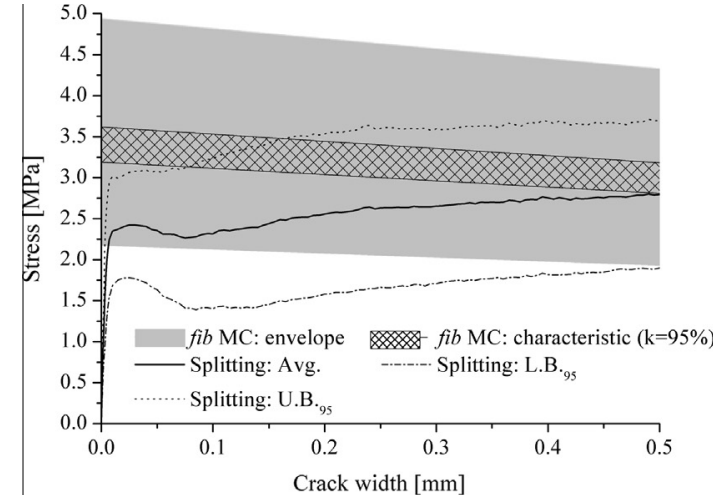

(a)

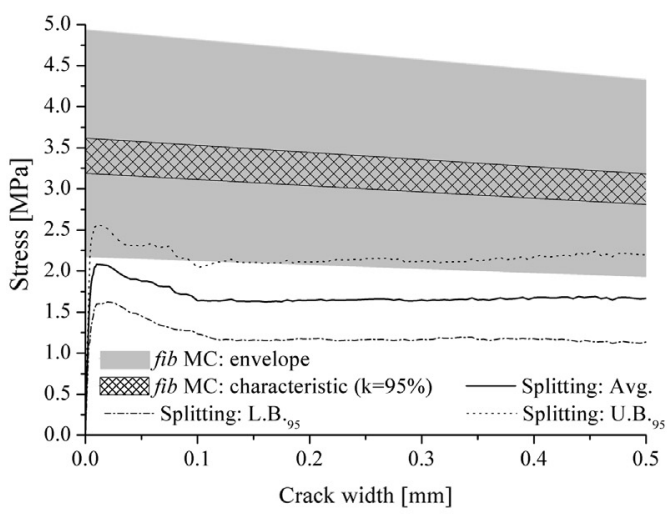

(c)

\section{Constitutive modelling the post-cracking behaviour of SFRSCC according to the fib MC 2010 approach}

\section{1. fib MC 2010 constitutive law}

fib MC 2010 proposes the stress versus crack width constitutive law represented in Fig. 15 with basis on the values of $f_{R, j}$ determined according to the approach described in Section 3. In the constitutive law represented in Fig. 15, $f_{\text {Fts }}$ represents the serviceability residual strength, defined as the post-cracking strength for serviceability crack openings, and $f_{F t u}$ represents the ultimate residual strength. These two parameters are calculated through the following equations $[44,45]$ :

$f_{\text {Fts }}=0.45 f_{R, 1}$

$f_{F t u}=f_{F t s}-\frac{w_{a c}}{\mathrm{CMOD}_{3}}\left(f_{F t s}-0.5 f_{R, 3}+0.2 f_{R, 1}\right) \geq 0$

The maximum crack opening accepted in structural design $\left(w_{a c}\right.$ presented in Fig. 15) was assumed equal to $0.3 \mathrm{~mm}$.

\section{2. fib MC 2010 model approach applied to the obtained experimental results}

In this research, the experimental data from the 3PBT was used to compute the envelopes and characteristics curves, i.e.; lower bound and upper bound with a confidence level $(k)$ equal to $95 \%$. Fig. 16 depicts a comparison between the experimental results obtained from the splitting tests and by using the model proposed

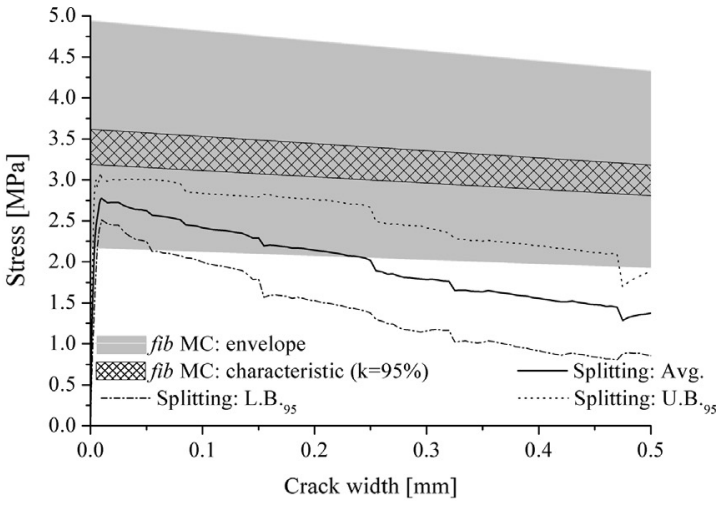

(b)

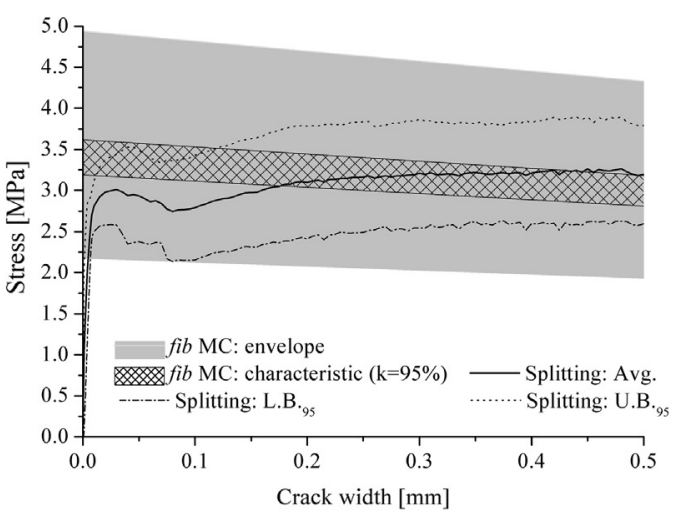

(d)

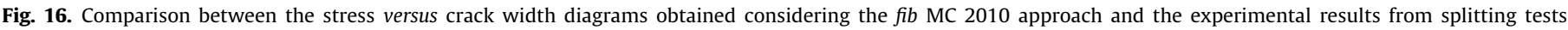

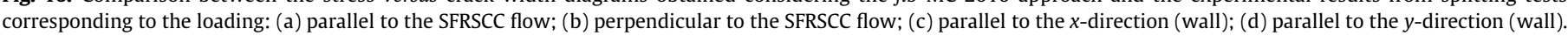




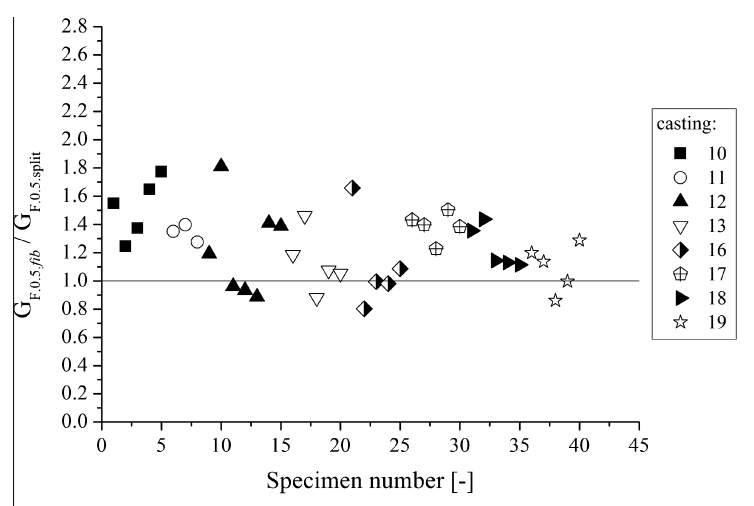

(a)

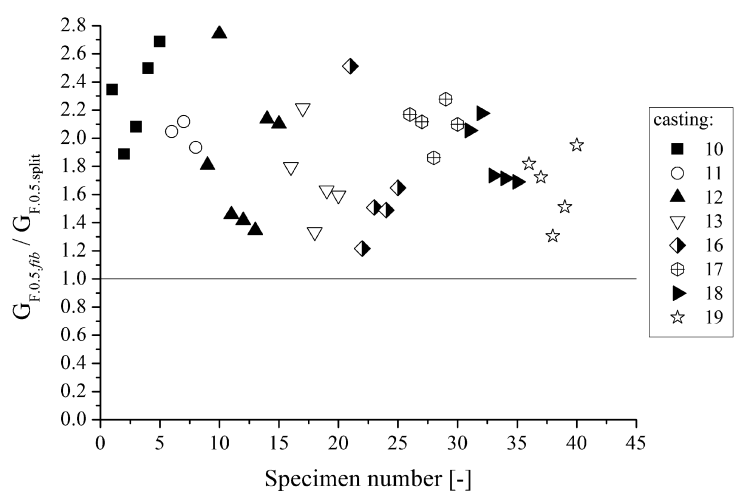

(c)

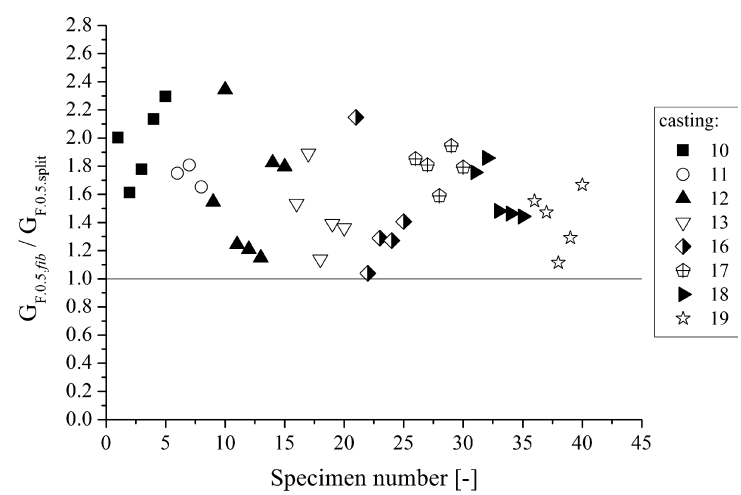

(b)

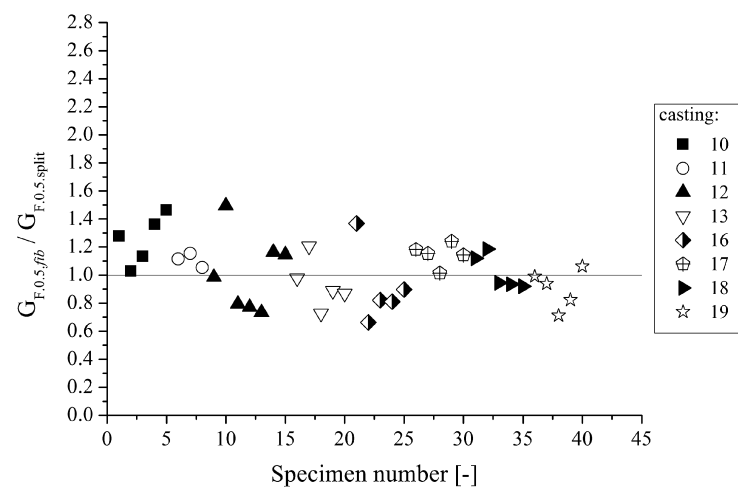

(d)

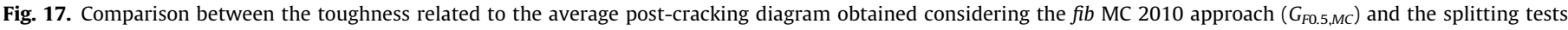

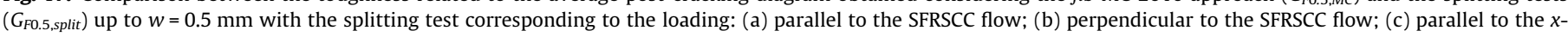
direction (wall); (d) parallel to the $y$-direction (wall).

by the fib Model Code 2010 formulation, up to a crack width of $0.5 \mathrm{~mm}$.

The results presented in Fig. 16 show a tendency of the approach of MC 2010 to overestimate the post-cracking tensile capacity of the adopted SFRSCC. This assertion is further confirmed in Fig. 17, that plots the ratios between the energy absorption capacity during the fracturing process, computed from the experimental data and the one calculated from the simplified MC 2010 approach. In this figure $G_{F 0.5, M C}$ is this energy, evaluated up to $0.5 \mathrm{~mm}$ of crack with and by using the MC approach, while $G_{F 0.5, \text { split }}$ is the corresponding one obtained from the splitting tests.

Figs. 16 and 17 interestingly show that the fib MC 2010 approach for the constitutive modelling of fibre reinforced concrete overestimates the energy absorption capacity even for the directions in which SFRSCC presents the uppermost energy absorption capacities (i.e.; with the loading applied parallel to the concrete flow), due to the flow induced orientation of fibres. This tendency was already observed by Salehian and Barros [57].

\section{Conclusions}

The research described herein presented an experimental investigation focused on the determination of the tensile constitutive behaviour of SFRSCC. A modified splitting test was proposed and making use of the developed test method, the influence of the flow driven orientation of fibres on the post-cracking behaviour of SFRSCC was assessed. Results from standard 3PBT method, proposed by RILEM TC 162-TDF for the characterization of regular FRC, were compared with the results obtained from specimens that are more representative of the actual structural element where the material is intended to be applied. Finally, the validity of fib MC 2010 approach for the constitutive modelling of SFRSCC applied to thin-section elements was questioned. From the research presented in this work, the following conclusions can be drawn:

- Although some undesirable failure modes were still obtained, the proposed test method is a promising procedure for the determination of the post-cracking behaviour of SFRSCC. Some optimization of the geometry of specimen (i.e.; diameter, dimensions of notches) is still necessary.

- For the materials and casting conditions used in this research, the fibre orientation seems to be highly affected by the concrete flow. Specifically for the flow conditions used in this research, i.e.; radial flow, the fibres tend to be oriented perpendicularly to the concrete flow.

- The post-cracking tensile behaviour of SFRSCC is affected by the fibre alignment resulting from the concrete flow and from the geometric characteristics of the structural element casted, but other parameters not covered in the present work also influence this behaviour, which deserves further research on the topic. Thus, the characterization of the material used in structural elements comprising SFRSCC should employ specimens that are geometrically representative of the actual structural element. Furthermore, to define the design value of the fracture properties the flow of concrete and the casting procedures should be taken into account.

- The method employed in this work, that consisted in obtaining the specimens from a plate with the same thickness of the structural element feeding the concrete in the centre of the 
plate and performing splitting tests with load applied parallel and perpendicular to the flow, is a promising procedure to determinate the values of the fracture parameters of SFRSCC to be adopted in the design of the thin-section structural elements. Having knowledge of the uppermost and the lowermost expected behaviour (i.e. obtained the proposed splitting tensile test with the load applied parallel and perpendicular to the concrete flow, respectively), and considering partial safety factors, the design values can be obtained.

- The fib MC 2010 approach for the constitutive modelling of fibre reinforced concrete seems to overestimate the energy absorption capacity even for the directions in which SFRSCC presents the uppermost energy absorption capacities (i.e.; with the loading applied parallel to the concrete flow), due to the flow induced orientation of fibres.

\section{Acknowledgements}

This work is part of the research project QREN number 5387, LEGOUSE, involving the companies Mota-Engil, CiviTest, the ISISE/University of Minho and PIEP. The first author would like to thank the FCT for the financial support through the PhD Grant SFRH/BD/64415/2009. The authors would like to express their sincere gratitude and appreciation to Ibermetais, Secil and SIKA, for supplying, respectively, the fibres, the cement and the superplasticizer, respectively.

\section{References}

[1] Kooiman AG. Modelling steel fiber reinforced concrete for structural design. PhD Thesis. Delft, The Netherlands: Delft University of Technology; 2000

[2] Markovic I. High-performance hybrid-fibre concrete: development and utilisation. PhD Thesis. Delft, The Netherlands: Delft University of Technology; 2006.

[3] Cunha VMCF. Steel fibre reinforced self-compacting concrete - from micromechanics to composite behaviour. PhD Thesis. Portugal: University of Minho; 2010.

[4] Laranjeira F. Design-oriented constitutive model for steel fiber reinforced concrete. PhD Thesis. Spain: Universitat Politècnica de Catalunya; 2010.

[5] Dupont D, Vandewalle L. Distribution of steel fibres in rectangular sections. Cem Concr Compos 2005;27(3):391-8.

[6] Gettu R, Gardner DR, Saldivar H, Barragán BE. Study of the distribution and orientation of fibers in SFRC specimens. Mater Struct 2005;38(1):31-7.

[7] Ferrara L, Park Y, Shah S. Correlation among fresh state behavior, fiber dispersion, and toughness properties of SFRCs. J Mater Civ Eng 2008;20(7):493-501.

[8] Vandewalle L, Heirman G, Van Rickstal F. Fibre orientation in self-compacting fibre reinforced concrete. In: 7th RILEM international symposium on fibre reinforced concrete 2008 (BEFIB 2008). Chennai: Curran Associates, Inc.; 2008

[9] Boulekbache B, Hamrat M, Chemrouk M, Amziane S. Flowability of fibrereinforced concrete and its effect on the mechanical properties of the material. Constr Build Mater 2010;24(9):1664-71.

[10] Ferrara L, Bamonte P, Caverzan A, Musa A, Sanal I. A comprehensive methodology to test the performance of steel fibre reinforced selfcompacting concrete (SFR-SCC). Constr Build Mater 2012;37:406-24.

[11] Ferrara L, Faifer M, Muhaxheri M, Toscani S. A magnetic method for non destructive monitoring of fiber dispersion and orientation in steel fiber reinforced cementitious composites. Part 2: Correlation to tensile fracture toughness. Mater Struct 2012;45(4):591-8.

[12] Torrents J, Blanco A, Pujadas P, Aguado A, Juan-García P, Sánchez-Moragues M. Inductive method for assessing the amount and orientation of steel fibers in concrete. Mater Struct 2012;45(10):1577-92.

[13] Ferrara L, Meda A. Relationships between fibre distribution, workability and the mechanical properties of SFRC applied to precast roof elements. Mater Struct 2006;39(4):411-20.

[14] Stähli P, Custer R, Mier JM. On flow properties, fibre distribution, fibre orientation and flexural behaviour of FRC. Mater Struct 2008;41(1):189-96.

[15] Martinie L, Rossi P, Roussel N. Rheology of fiber reinforced cementitious materials: classification and prediction. Cem Concr Res 2010;40(2):226-34.

[16] Ferrara L, Faifer M, Toscani S. A magnetic method for non destructive monitoring of fiber dispersion and orientation in steel fiber reinforced cementitious composites-Part 1: method calibration. Mater Struct 2012;45(4):575-89.

[17] Abrishambaf A, Barros JAO, Cunha VMCF. Relation between fibre distribution and post-cracking behaviour in steel fibre reinforced self-compacting concrete panels. Cem Concr Res 2013;51:57-66.
[18] Švec O, Žirgulis G, Bolander JE, Stang H. Influence of formwork surface on the orientation of steel fibres within self-compacting concrete and on the mechanical properties of cast structural elements. Cem Concr Compos 2014(0).

[19] RILEM TC 162-TDF. Uni-axial tension test for steel fibre reinforced concrete. Mater Struct 2001:34(1):3-6.

[20] RILEM TC 162-TDF. Bending test. Mater Struct 2002;35(9):579-82.

[21] CEN. EN 14651: test method for metallic fibered concrete - measuring the flexural tensile strength (limit of proportionality (LOP), residual). Brussels: European Committee for Standardization; 2005.

[22] CEN. EN 14488-3: testing sprayed concrete. Flexural strengths (first peak, ultimate and residual) of fibre reinforced beam specimens. Brussels: European Committee for Standardization; 2006.

[23] CEN. EN 14488-5: testing sprayed concrete. Determination of energy absorption capacity of fibre reinforced slab specimens. Brussels: European Committee for Standardization; 2006

[24] Hordijk D. Local approach to fatigue of concrete. Delft, The Netherlands: Delft University of Technology; 1991.

[25] Barros JAO. Behaviour of fibre reinforced concrete, experimental analysis and numerical modelling. Porto: University of Porto; 1995.

[26] Barragán BE. Failure and toughness of steel fiber reinforced concrete under tension and shear. Barcelona: UPC; 2002.

[27] Pereira EB, Fischer G, Barros JAO. Direct assessment of tensile stress-crack opening behavior of strain hardening cementitious composites (SHCC). Cem Concr Res 2012;42(6):834-46.

[28] Shah SP, Swartz SE, Ouyang C. Fracture mechanics of concrete: applications of fracture mechanics to concrete, rock and other quasi-brittle materials. John Wiley \& Sons, Inc.; 1995.

[29] Van Mier JGM. Fracture processes of concrete: assessment of material parameters for fracture models. Boca Raton (FL): CRC Press; 1997.

[30] Bažant PZ, Planas J. Fracture and size effect in concrete and other quasibrittle materials. New directions in civil engineering. Boca Raton (FL): CRC Press; 1998.

[31] ASTM Standard C1550. Standard test method for flexural toughness of fiber reinforced concrete (using centrally loaded round panel). West Conshohocken, PA: ASTM International; 2010.

[32] di Prisco M, Plizzari G, Vandewalle L. Fibre reinforced concrete: new design perspectives. Mater Struct 2009;42(9):1261-81.

[33] Ozyurt N, Mason TO, Shah SP. Correlation of fiber dispersion, rheology and mechanical performance of FRCs. Cem Concr Compos 2007;29(2):70-9.

[34] Carmona S, Aguado A. New model for the indirect determination of the tensile stress-strain curve of concrete by means of the Brazilian test. Mater Struct 2012;45(10):1473-85.

[35] Brühwiler E, Wittmann FH. The wedge splitting test, a new method of performing stable fracture mechanics tests. Eng Fract Mech 1990;35(13): $117-25$.

[36] di Prisco M, Ferrara L, Lamperti ML. Double edge wedge splitting (DEWS): an indirect tension test to identify post-cracking behaviour of fibre reinforced cementitious composites. Mater Struct 2013;46(11):1893-918.

[37] Ozyurt N, Mason TO, Shah SP. Non-destructive monitoring of fiber orientation using AC-IS: an industrial-scale application. Cem Concr Res 2006:36(9):1653-60.

[38] Stähli P, van Mier JGM. Manufacturing, fibre anisotropy and fracture of hybrid fibre concrete. Eng Fract Mech 2007;74(1-2):223-42.

[39] Torrijos MC, Barragán BE, Zerbino RL. Placing conditions, mesostructural characteristics and post-cracking response of fibre reinforced self-compacting concretes. Constr Build Mater 2010;24(6):1078-85.

[40] Akcay B, Tasdemir MA. Mechanical behaviour and fibre dispersion of hybrid steel fibre reinforced self-compacting concrete. Constr Build Mater 2012;28(1):287-93.

[41] Zerbino R, Tobes JM, Bossio ME, Giaccio G. On the orientation of fibres in structural members fabricated with self compacting fibre reinforced concrete. Cem Concr Compos 2012;34(2):191-200.

[42] Laranjeira F, Aguado A, Molins C, Grünewald S, Walraven J, Cavalaro S. Framework to predict the orientation of fibers in FRC: a novel philosophy. Cem Concr Res 2012;42(6):752-68.

[43] Cunha VMCF, Barros JAO, Sena-Cruz JM. An integrated approach for modelling the tensile behaviour of steel fibre reinforced self-compacting concrete. Cem Concr Res 2011:41(1):64-76.

[44] fib. Model Code 2010 - final draft, volume 1. fédération internationale du béton/International Federation for Structural Concrete (fib); 2012.

[45] fib. Model Code 2010 - final draft, volume 2. fédération internationale du béton/International Federation for Structural Concrete (fib); 2012.

[46] RILEM TC 162-TDF. Bending test. Mater Struct 2000;33(1):3-5.

[47] RILEM TC 162-TDF. $\sigma$ - $\varepsilon$-Design method. Mater Struct 2000;33(2):75-81.

[48] RILEM TC 162-TDF. $\sigma-\varepsilon$-Design method. Mater Struct 2003;36(8):560-7.

[49] Pereira EB, Barros JAO, Ribeiro A, Cunha VMCF, Antunes JAB. Self-compacting steel fibre reinforced concrete for precasted sandwich panels - experimental and numerical research. In: di Prisco M, Felicetti R, Plizzari GA, editors. 6th International RILEM symposium on fibre-reinforced concretes (BEFIB 2004). Ancona, Italy: RILEM; 2004. p. 15-7.

[50] EFNARC. The European guidelines for self-compacting concrete; 2005

[51] LNEC E397. Betões. Determinação do módulo de elasticidade em compressão (technical report). Lisbon: Laboratório Nacional de Engenharia Civil (LNEC); 1993.

[52] RILEM TC 14-CPC. Modulus of elasticity of concrete in compression (CPC8). Mater Struct 1975;6(30):25-7. 
[53] ASTM C469. Standard test method for static modulus of elasticity and Poisson's ratio of concrete in compression. Annual book of ASTM standards (0402). West Conshohocken, Pennsylvania: American Society of Testing Materials (ASTM); 1994.

[54] Bentur A, Mindess S. Fibre reinforced cementitious composites. second ed. Taylor \& Francis; 2006.

[55] Lameiras R, Barros J, Valente IB, Azenha M. Development of sandwich panels combining fibre reinforced concrete layers and fibre reinforced polymer connectors. Part I: conception and pull-out tests. Compos Struct 2013:105:446-59.

[56] Lameiras R, Barros J, Azenha M, Valente IB. Development of sandwich panels combining fibre reinforced concrete layers and fibre reinforced polymer connectors. Part II: evaluation of mechanical behaviour. Compos Struct 2013;105:460-70.

[57] Salehian H, Barros JAO. Design and testing elevated steel fibre reinforced selfconcrete slabs (accepted to be published). Cem Concr Compos 2014. 